\title{
Innovations in Information Technology and the Mortgage Market
}

\author{
Bulent Guler *
}

February 15, 2010

\begin{abstract}
In this paper, I study the effects of innovations in information technology on the housing market. Specifically, I focus on the improved ability of lenders to assess the credit risk of home buyers, which has become possible with the emergence of automated underwriting systems in the United States in the mid-1990s. I develop a standard life-cycle model with incomplete markets and idiosyncratic income uncertainty. I explicitly model the housing tenure choice of the households: rent/purchase decision for renters and stay/sell/default decision for homeowners. Risk-free lenders offer mortgage contracts to prospective home buyers and the terms of these contracts depend on the observable characteristics of households. Households are born as either good credit risk types - having a high time discount factor - or bad types - having a low time discount factor. The type of the household is the only source of asymmetric information between households and lenders. I find that as lenders have better information about the type of households, the average downpayment fraction decreases together with an increase in the average mortgage premium, the foreclosure rate, and the dispersions of mortgage interest rates and downpayment fractions, which are consistent with the trends in the housing market in the last 15 years. From a welfare perspective, I find that better information, on average, makes households better off.
\end{abstract}

Keywords: Housing, mortgage contract, asymmetric information, default

JEL Classifications: D82, D91, E21, H21

* Department of Economics, Indiana University at Bloomington, bguler@indiana.edu. I owe a debt of gratitude to my advisors Fatih Guvenen and P. Dean Corbae for their invaluable encouragement and support. I greatly benefited from conversations with Yavuz Arslan, Satyajit Chatterjee, Burhanettin Kuruscu, Marcin Peski, Jose-Victor RiosRull, Juan M. Sanchez, Gianluca Violante, and Thomas Wiseman. All errors are mine. 


\section{Introduction}

The US housing market has witnessed important changes since the mid-1990s. Arguably, the most prominent technological change during this time was the emergence of automated underwriting systems (hereafter AUS), which allowed a better assessment of the credit risks of home buyers. In particular, advances in information technology (e.g., the rapid decline in the cost of storing and transmitting credit information) have enabled access to more comprehensive data on households, which in turn increased the predictive power of credit scores, thereby allowing lenders to assess the credit risk of home buyers more precisely. Accompanying these improvements in information technology, the housing market has experienced changes along some key dimensions. As reported in Table 1, a comparison of the 1991-1995 period and 2002-2006 period reveals that (i) the foreclosure rate has increased, (ii) average mortgage premium has gone up, (iii) average downpayment fraction

has decreased, and (iv) the dispersions of mortgage interest rates and downpayment fractions have risen up.

Table 1: Summary Statistics*

\begin{tabular}{lcc}
\hline \hline Statistic & $\mathbf{1 9 9 1 - 1 9 9 5}$ & $\mathbf{2 0 0 2 - 2 0 0 6}$ \\
\hline Foreclosure rate & $0.33 \%$ & $0.44 \%$ \\
Mortgage premium & $0.32 \%$ & $0.52 \%$ \\
Average downpayment fraction & $14.5 \%$ & $8.9 \%$ \\
Coef of variation-int rate & 0.159 & 0.203 \\
Coef of variation-downpayment & 1.28 & 3.55 \\
\hline \hline
\end{tabular}

* Downpayment and mortgage interest rate data are from American Housing Survey and calculated for 30-year fixed rate mortgages. Mortgage premium, measured as the difference between 30-year fixed rate mortgage and AAA corporate bond yield, is from Federal Reserve Board. Foreclosure data is from Mortgage Bankers Association.

In this paper, I explore the effect of innovations in information technology - specifically, the increased ability of lenders to assess the credit risk of home buyers - on the housing market. I develop a standard life-cycle model with incomplete markets and idiosyncratic labor income uncertainty. I also model the housing tenure choice. There are two types of households: those with a high time discount factor (ie., the "good" type) and those with a low time discount factor (ie., the "bad" type). Households are born as renters with ex-ante heterogeneity in income and wealth. Every period, renters decide whether or not to purchase a house. There is a continuum of risk-neutral lenders who offer mortgage contracts to prospective home buyers. A mortgage contract consists of a mortgage interest rate, loan amount, mortgage repayment schedule and maturity. Mortgages are fully amortizing, that is, homeowners have to pay the mortgage back in full until the end of the mortgage contract, as specified by the maturity. However, homeowners also have the option to sell 
their houses or default on the mortgage and return to the rental market. Selling a house is different from defaulting, because a seller has to pay back the outstanding mortgage balance to the lender whereas a defaulter has no obligation. Therefore, default occurs in equilibrium as long as the selling price is lower than the outstanding mortgage debt. Upon default, the household becomes a renter again and is excluded from the mortgage market for a certain number of years as punishment.

There is free entry into the credit market, so in equilibrium lenders make zero profit on each contract. Since mortgages are long-term contracts, it is essential for the lenders to infer the default probability of each household at every date and state, which depends on the income risk as well as on the type of each household. Clearly, given an income realization, a household with a low time discount factor (bad type) has a higher probability of default, since she values the benefit of homeownership less compared to the good types. I explore two information structures. In one economy, lenders cannot observe the types although they can observe all the other characteristics of the household. This creates asymmetric information between the lenders and households, and I call this the asymmetric information economy (AI). In the other economy, lenders can observe all the characteristics of the household and therefore information is symmetric (hence, called symmetric information economy, SI) $!^{1}$

I interpret the AI economy as representing the US economy before the emergence of automated underwriting systems (before mid-1990s), whereas the SI economy represents the more recent period with AUS (mid-2000s). Because these two time periods also differ in average interest rates and housing prices, each economy is calibrated to match these two empirical targets in their respective time period. The results indicate that the transition from the AI economy to the SI economy decreases the downpayment fraction and increases the mortgage premium, foreclosure rate, and homeownership rate, which are consistent with the current changes in the mortgage market. Moreover, consistent with the data, the transition brings an increase in the dispersion of the mortgage interest rates and downpayment fractions. However, the levels of the dispersion of mortgage interest rates that the model generates are much lower than their data counterparts. This is mainly due to omission of several important risk factors (i.e., risk-free interest rate risk, house price risk) in the model.

Because the AI and SI economies also differ in the average interest rate and housing price, I conduct the following (counterfactual) experiment to isolate the role of information technology. Basically, I simulate the AI economy with the same set of parameters in the SI economy. The results show that information structure is the main driving force behind the increase in the dispersion of mortgage interest rates and downpayment fractions as well as having an important role in the

\footnotetext{
${ }^{1}$ Chatterjee, Corbae and Rios-Rull $(2007,2008)$ build a model of reputation in credit markets and show how credit scores are informative about the type of the households in equilibrium. Good types are patient and value reputation more compared to the bad types. As a result, the credit score, which tracks the history of the ability and willingness of the household to make debt payments, becomes very informative in differentiating the households. However, due to the curse of dimensionality of such a model, I do not explicitly model the credit scores. Instead, I assume that the emergence of credit scores has enabled lenders to fully observe the type of the households.
} 
increase of the mortgage premium, the foreclosure rate, and the decrease in the downpayment fraction. Risk-free interest rate and house price are more important in explaining the increase in the homeownership rate and the decrease in the downpayment fraction. A higher foreclosure rate does not mean that lenders and households are worse off in the SI economy. When I measure the welfare gain of being born into the SI economy as opposed to the AI economy, the gain, in consumption equivalent terms, is between $0.25 \%$ and $0.29 \%$ depending on whether I use pooling contracts or separating contracts as equilibrium contracts in the AI economy. Furthermore, the zero-profit restriction on the contracts ensures that, ex-ante, lenders are indifferent between both economies. I, finally, check the robustness of the results to the selection of equilibrium in the AI economy. The counterfactual shows the equilibrium with pooling contracts. To explore the effect of an alternative equilibrium, I solve the AI economy with separating contracts. The new equilibrium with separating contracts shows very similar effects as the equilibrium with pooling contracts.

In the AI economy, lenders cannot observe the types and they face an adverse selection problem. This puts additional constraints on the contracts offered in the AI economy. The transition from the AI economy to the SI economy, both in the extensive margin and intensive margin, makes the credit terms more relaxed. In the extensive margin, those low income households who are rationed out in the AI economy become eligible for mortgages. Since these households are income constrained, they demand for lower downpayment fraction which requires higher mortgage premium. In the intensive margin, since bad types are, now, perfectly observed they get contracts that have lower downpayment fraction at the cost of higher mortgage premium2. Moreover, since good types face lower mortgage premium, they also demand for lower downpayment fraction loans. As a result downpayment fraction decreases whereas mortgage premium and homeownership rate increase. Since the new home purchasers are low income households and average downpayment fraction decreases together with an increase in the mortgage premium, the default risk in the market increases. Thus, the foreclosure rate increases.

There is a growing empirical literature suggesting that innovations in the mortgage market are the main reasons for the recent changes in the housing market. Testing the forecasting relationship between housing spending and future income, Gerardi, Rosen and Willen (2006) find that recent developments in the mortgage market have ensured that households have been more able to buy houses whose values are in line with their long-term income prospects. Mian and Sufi (2008) document that high unfulfilled demand zip codes experienced relative declines in mortgage application denial rates and mortgage interest rates and relative increases in mortgage credit and house prices despite the negative relative income and employment growth in these zip codes. They also find that the growth of securitization was significantly higher in high unfulfilled demand zip codes, suggesting a possible role of supply side changes in the mortgage market. Finally, using the American

\footnotetext{
${ }^{2}$ Note that households face a trade-off between the downpayment fraction - short-term debt - and mortgage payment - long-term debt - during the house purchase. Bad types - impatient households - favor a decrease in the downpayment fraction more than an decrease in the mortgage payment compared to the good types - patient households.
} 
Housing Survey data, Doms and Krainer (2007) find that housing expenditures of the households facing the greatest financial constraints have increased substantially using, particularly, the newly designed mortgages.

Although, on the empirical side, financial innovations in the mortgage industry and its impact on the market and households seem to be well documented, the literature thus far has paid little attention to modeling this link. In a stylized model, Ortalo-Magne and Rady (2006) show the effect of credit constraints, especially the effect of downpayment requirement, on the extensive and intensive margin of homeownership. Chambers, Garriga and Schlagenhauf (2008), in a quantitative framework, analyze the effect of financial innovations on the homeownership rate. They find that the key to understanding the increase in the homeownership rate, especially for young households, is the expansion of the set of mortgage contracts. Nevertheless, their way of modeling the terms of mortgage credit is in a reduced form and cannot explain the reason for the expansion of the mortgage credit. Moreover, they do not model the default option.

The equilibrium model of mortgage credit and default used in this paper is related to the equilibrium models of unsecured borrowing and bankruptcy 3 . Closely related to my paper are three papers influenced by Narajabad (2007): Sanchez (2008), Athreya, Tam and Young (2008), and Livhits, MacGee and Tertilt (2008) who explore the effects of innovations in the unsecured credit market. These papers show that a transition from a partial information economy to a full information economy results in an increase in consumer bankruptcies and debt which is consistent with the trend in the data. These papers analyze the unsecured credit market and borrowing is only for one period. Different from these models, I analyze the mortgage market characterized by secured borrowing and long-term maturity contracts which requires us to model the lender's problem recursively.

This paper is organized as follows: Section 2 documents some recent innovations in the mortgage market, especially focusing on the emergence of credit scoring technology and its impacts on the market. Section 3 describes the environment and sets up the model. Section 4 presents the main results of the model together with a counterfactual experiment separating the impact of the change in information structure. It also presents the results for an alternative equilibrium definition. Finally, Section 5 concludes with directions for future work. The Appendix presents a simpler model to analyze the potential existence problem.

\section{Innovations in Information Technology}

There are three basic components of single-family mortgage underwriting: the value of the collateral, the ability of the borrower to make monthly mortgage payments and the willingness of the borrower

\footnotetext{
${ }^{3}$ Chatterjee, Corbae, Nakajima (2007) and Livhits, MacGee and Tertilt (2007) are some prominent examples of such models.
} 
to pay back outstanding mortgage debt. They are summarized as the traditional "three C's": Collateral, Capacity and Credit. The loan-to-value ratio is the measure of the collateral, which is basically measured by the downpayment fraction and the real value of the house. Capacity is useful to understand the ability of the borrower to make the monthly mortgage payments and is measured through several economic variables regarding the home buyer such as debt-to-income ratio, debtservice ratio,employment status, and savings. Lastly, credit shows both the ability and willingness of the borrower to pay back the debt and is assessed through a credit report summarizing the historical performance of the home buyer in the credit market.

Until the mid 1990's, credit was the missing piece of the three C's. Insufficient available credit data for individuals was the main reason for the absence of credit reports in mortgage underwriting. Unlike unsecured credit, mortgages are long-term contracts and larger amount of loans are at risk or fraudulent. Knowing the ability of the home buyer to make the periodic mortgage payments is the most important information for the lenders. The home buyer's loyalty to the payments strongly depends on his credit history, which captures the historical performance of the individual in the credit market. Borrowers with poor credit records go into mortgage default at much higher rates than borrowers with good credit records. Since insufficient credit report data may be misleading, lenders hesitated to use the credit reports for a long time. Straka (2000) shows the relationship between credit scores and default rates using a 1995 assessment of a large sample of Freddie Mac loans which were originated between 1990 and 1991. The result shows that in a weak regional housing market, a mortgage holder with a credit score, measured as a FICO score, smaller than 620 is 17 times more likely to default than a mortgage holder with a credit score higher than 760 . He also shows that even in a strong regional housing market, credit scores have a great predictability of mortgage default 4 .

As the IT revolution has made computers part of our daily life, enabled data storage to become more efficient and less expensive and allowed computer networking through local area networks and the internet, there has been an explosion in the growth of credit report in the late 1980s and early 1990:5. As a result we see a shift in the mortgage landscape. Long-time dominant manual and decentralized underwriting and origination systems requiring labor and paper intensive loan processing and risk assessment and lasting for weeks and even months have been rapidly replaced by automated and centralized underwriting systems based on credit scores, statistical model loan processing and risk evaluations which result in in-minute decisions and same-day closings. Before 1995, negligible amount of mortgage lenders had been using automated underwriting systems. In 1995, FreddieMac and FannieMae published industry letters that endorsed the use of credit scores to assess credit quality. In subsequent years, the mortgage industry has experienced a growing

\footnotetext{
${ }^{4}$ See also Pennington-Cross (2003), Cutts and Green (2004) and Barakova, Bostic, Calem, and Wachter (2003) for further evidence of predictive power of credit scores in mortgage repayment and default.

${ }^{5}$ See Hunt (2005) on the evolution of consumer credit reports and Lacour-Little (2000) and Pafenberg (2004) for the adoption of credit reporting in the mortgage industry.
} 
adoption of automated underwriting systems which rely on credit scores and statistical models

This transition has brought two innovations to the mortgage industry: usage of credit scoring and automation of the underwriting process. These innovations have increased the ability of the lenders to assess the credit risk of the home buyers. Straka (2000) documents the result of an experiment which compares the performance of manual -without credit scores- and automated with credit scores- underwriting. A pool of 1000 mortgages that originated between 1993 and 1994, were evaluated both by manual and automated underwriting system ${ }^{7}$. Although both underwriting systems chose half of the loans as investment-quality loans, the overlapping was quite few. After three years, the performance of the loans was compared in four categories (share of the 30 days, 60 days, 90 days delinquent loans and foreclosed loans) and the results were striking. While investment quality loans determined by automated underwriting system performed quite better than the non-investment quality loans, there was essentially no difference between the investment and non-investment quality loans determined by manual underwriting in terms of delinquency rates. The results were quite striking, especially in terms of foreclosure rates . Non-investment quality loans ended up in foreclosure eight times more than investment quality loans according to the automated underwriting system selection. However, according to manual underwriting selection, investment quality loans ended up in foreclosure seventeen times more than the non-investment quality loans 8 .

\section{Model}

I begin by describing the environment agents face in the economy. I then specify the decision problems of households and lenders. I finally define the equilibrium.

\subsection{Environment}

The economy is populated by overlapping generations of $J$ period lived households and a continuum of lenders. Each generation has a continuum of households. Time is discrete and households live for a finite horizon. There is no aggregate uncertainty. Households face idiosyncratic uncertainty in labor income and markets are incomplete. There is mandatory retirement at the age $J_{r}$. Retirement income is constant and depends on the income of the household at age $J_{r}$ and the average income

\footnotetext{
${ }^{6}$ According to Pafenberg (2004), among the loans Freddie Mac and Fannie Mae purchased from enterprises, the percentage of mortgages evaluated using automated underwriting systems by the enterprises prior to the purchase increased from $10 \%$ to $60 \%$ between 1997 and 2002 .

${ }^{7}$ Straka (2000) notes that the assessment of all mortgages through manual underwriting lasted six months while through automated underwriting it lasted only a couple of hours.

${ }^{8}$ Gates, Perry and Zorn (2002) also provide a comparison of manual and automated underwriting systems. They also show how automated underwriting outperforms manual underwriting in terms of predicting delinquency and foreclosure.
} 
in the economy. They can save at an exogenously given interest rate $r$ but they're not allowed to make unsecured borrowing. Ex-ante, households differ in three dimensions: initial asset, income and discount factor. Initial income is assumed to be the stationary distribution and the initial asset-income ratio is assumed to be log-normally distributed. There are two types of households: good types having high time discount factor and bad types having low time discount factor.

Households live in houses, which they can either rent or own. At the beginning of each period, a household is in one of the three housing statuses: inactive renter, active renter, or homeowner. Active renters are always allowed to purchase a house, while inactive renters are only allowed with a certain probability $\delta$. Both rental price and purchase price for the houses are exogenous and constant9. The size of the house is fixed, i.e. there is no upgrading or downgrading of the house size. However, since houses are big and expensive, their purchase is only through mortgages, which is also the only source of borrowing in the economy. A mortgage contract is a combination of interest rate and loan amount, specified by the downpayment fraction and house value. Maturity of the mortgages is assumed to be the remaining life time of the household until retirement 10 . Lenders only offer fixed-payment mortgages, so the payment is constant throughout the life of the mortgage $£^{11}$. There is no mortgage refinancing or home-equity line of credit. Homeowners have the option to default at any time period. The details of the model are explained below.

\subsubsection{Households}

Households derive utility from consumption and housing services. Preferences are represented by

$$
E_{0}\left[\sum_{j=1}^{J_{r}} \beta_{i}^{j-1} u_{k}\left(c_{j}\right)+\beta_{i}^{J_{r}+1} W\left(w_{J_{r}}, y_{J_{r}}\right)\right]
$$

where $\beta_{i}<1$ is the discount factor for type $i \in\{g, b\}$ agent, $c$ is the consumption and $k$ is the housing status: renter or homeowner. $W$ represents the value function of the household at

\footnotetext{
${ }^{9} \mathrm{I}$ implicitly assume that the supply of rental and owner-occupied units is perfectly elastic. There is a fixed unit of housing and all units can be converted into a rental or owner-occupied unit without any cost. These assumptions ensure that the price stays constant and all the response to a demand increase occurs in the extensive margin as an increase in the homeownership rate.

${ }^{10}$ Maturity of the mortgage, in reality, is a choice variable. However, in the current context to save from an extra state variable, I avoid this choice for now. Moreover, I assume that all homeowners are forced to sell their houses by retirement and spend their remaining life as renters. Since after retirement there is no uncertainty, housing tenure choice becomes uninteresting. So, to simplify the problem of the retirees, I ignore their housing tenure choice and force them to live as renters. This formulation will greatly simplify the computation of the value function at the time of retirement.

${ }^{11}$ Since I assume constant interest rate, traditional fixed rate mortgages and adjustable rate mortgages would have fixed payments throughout the life of the mortgage and they both fall into this category. These mortgages are not necessarily optimal contracts. A more convenient formulation should also include the mortgage payment as part of the contract and be determined in equilibrium. However, for simplicity I abstract from that and focus on the fixed payment mortgage contracts which are the dominant mortgages in the U.S. history.
} 
retirement given wealth $w_{J_{r}}$ and income $y_{J_{r}} \sqrt{12}$. There are two types of households: good types and bad types. Good types have a higher time discount factor than the bad types: $\beta_{g}>\beta_{b}$. Types are fixed and the measure of the good types in the economy is $\mu$. The house size is fixed and the utility from housing services is summarized as two different utility functions: one for the renter, $u_{r}$ and one for the homeowner, $u_{h}$. A homeowner receives a higher utility than a renter from the same consumption: $u_{h}(c)>u_{r}(c)$.

The log of the income before retirement is a combination of a deterministic and a stochastic component whereas after retirement it is the $\lambda$ fraction of the income at age $J_{r}$ plus $\eta$ fraction of the average income in the economy, $\bar{y}$ :

$$
\begin{aligned}
y_{j}\left(j, z_{j}\right) & =\left\{\begin{array}{cc}
\exp \left(f(j)+z_{j}\right) & \text { if } j \leq J_{r} \\
\lambda y_{J_{r}}\left(J_{r}, z_{J_{r}}\right)+\eta \bar{y} & \text { if } j>J_{r}
\end{array}\right\} \\
z_{j} & =\rho z_{j-1}+e_{j}
\end{aligned}
$$

where $y_{j}$ is the income at age $j, f(j)$ is the age-dependent deterministic component of the $\log$ income, and finally $z_{j}$ is the stochastic component of the log income. The stochastic component is modeled as an $A R(1)$ process with $\rho$ as the persistency level. The innovation to the stochastic component, $e_{t}$, is assumed to be i.i.d and normally distributed: $N\left(0, \sigma_{e}^{2}\right)$. Households can save to smooth their consumption at the constant risk-free interest rate $r$, but there is no unsecured borrowing.

Households start the economy as active renters, and can purchase a house and become an owner at any period in time. However, an inactive renter is only allowed to purchase a house with probability $\delta$. With $(1-\delta)$ probability, she is forced to live as a renter. Since houses are expensive items, their purchases can only be done through securitized borrowing: mortgages. A purchaser chooses among a menu of feasible mortgage contracts, each specified with a loan amount and interest rate ${ }^{13}$. Since the mortgages are fixed-payment mortgages, the contract together with the maturity, remaining time to retirement, determine the periodic mortgage payments. As long as the household stays in the house, she has to make these payments. The homeowner has also the option to sell the house at any time period. However, selling the house is costly. There are some costs (transaction costs and maintenance costs) associated with selling the house. So, a seller incurs a proportional cost, $\varphi$, of the house price. Moreover, a seller has to pay the outstanding mortgage debt back to the lender.

There is another option for the household to quit the house. She can default on the mortgage. A defaulter has no obligation to the lender. Upon default, the lender seizes the house, sells it

\footnotetext{
${ }^{12}$ Since there is no housing tenure choice and uncertainty after retirement, household's problem is trivial and can be calculated analytically.

${ }^{13}$ Not every combination of mortgage interest rate and loan amount is feasible for the household. Lenders' inference about the type of the household and competition among lenders restrict the contracts offered to the household.
} 
and pays back, if any, to the defaulter the amount net of outstanding mortgage debt and costs associated to selling the house. The lender's cost of selling the house is $\varphi$ fraction of the house price. What makes default appealing for the household is the fact that a defaulter has no obligation to the lender whereas a seller has to pay back the debt in full. The same fact puts a risk of loss on the lender. The lender incurs a loss if the net value of the house is smaller than the outstanding debt upon default.

Default is not without any cost to the household. A defaulter becomes an inactive renter and can only enter to the housing market with probability $\delta$. Lastly, at the end of the life cycle, homeowner sells the house and enjoys the utility from consuming the selling price. Again, the seller loses $\varphi$ fraction of the house price during the transaction.

\subsubsection{Lenders}

There is a continuum of lenders and financial markets are perfectly competitive. Lenders are riskneutra 14 . The economy is assumed to be an open economy and the risk-free interest rate, $r$, is set exogenously. Mortgage contracts are long-term contracts and the maturity of the contract is directly determined by the time to retirement, which is assumed to be certain and observable. Lenders have full commitment to the contract and renegotiation is not allowed.

Each contract is characterized by a loan amount, $d$, and interest rate, $r_{m}$. Since the households can default on the mortgage at any time period, and transaction and further costs make the loan not fully securitized, lenders face a risk of loss on mortgage loans. Moreover, there is an additional per period servicing cost for mortgage loans, $\tau$, which is assumed to be proportional to the loan amount.

\subsubsection{Timing}

The timing of the events is the following: Households are born as active renters. For any other period, the household starts the period either as a homeowner, an active renter or an inactive renter. At the beginning of each period, households realize their income shock and decide about their housing statuses for the current period.

An active renter has two choices: continue to rent or purchase a house. If she decides to continue to rent, she pays the rental price, makes her consumption and saving choices, and reaches to the next period as an active renter. If she decides to buy a house, she goes to a lender. The lender offers a menu of mortgage contracts depending on the observable of the household 15 . The household

\footnotetext{
${ }^{14}$ Securitization of mortgages helped lenders to diversify the risk they face and liquidate their asset holding. However, risk-neutrality assumption eliminates such benefits of the securitization.

${ }^{15}$ Note that in SI economy and AI economy with pooling contracts, the lender only offers one contract depending on the observable of the household. In the AI economy with separating contracts, the lender offers two contracts to separate the good type and the bad type.
} 
chooses the mortgage contract that maximizes her utility. Lastly, she pays the downpayment and periodic mortgage payment implied by the mortgage contract, makes her consumption and saving choices, and reaches to the next period as a homeowner.

A homeowner has three choices. If she decides to stay in the current house, she pays the fixed mortgage payment, makes her consumption and saving choices, and starts the next period again as a homeowner. If she decides to sell the house, she receives the selling price, pays the outstanding mortgage debt back to the lender, makes her consumption and saving choices and begins the next period as an active renter. If she decides to default, she receives any positive remaining balance the selling price of the house to the lender minus the outstanding mortgage debt - from the lender, makes her consumption and saving choices, and starts the next period as an active renter with $\delta$ probability and inactive renter with $(1-\delta)$ probability.

An inactive renter has no housing tenure choice. She is forced to live as a renter. So, she pays the rental price, and only makes her consumption and saving choices and starts the next period as an active renter with $\delta$ probability and inactive renter with $(1-\delta)$ probability.

\subsubsection{Information Structure}

As I mentioned above, the menu of mortgage contracts offered by the lender depends on the observable of the household. I model the information structure in two different ways. In the first economy, which I call as the "Asymmetric Information" (AI) economy, the lender can observe the current characteristics of the household except the type - discount factor. I also assume the history of the household is not observable. The lender only knows the initial distribution of the households and can infer the type of the household given the current period observable. This informational asymmetry between households and lenders creates the problem of adverse selection. Since the lender cannot observe the type, any contract designed for the good type is also available for the bad type with the same observable.

In the second economy, which I call as the "Symmetric Information" (SI) economy, the lender observes all the characteristics of the household. This feature of the economy enables the lenders to separate all the households, evaluate the default risk of each household and set mortgage prices at the household level. So, in the SI economy, mortgage pricing is fully individualized, whereas in the AI economy, lenders face a pool of households with the same characteristics but different types.

\subsection{Decision Problems}

I now turn to the recursive formulation of the household's and lender's problem. Note that since the mortgages are long-term contracts, the lender's problem also has dynamic structure. The lender has to calculate the default risk of the household through the life of the mortgage. Here, I first 
start with the recursive formulation of the household's problem, then I set up the lender's dynamic programming problem which is also closely related to the household's problem.

\subsubsection{Household's Problem}

I only focus on household's problem before retirement. The value function at the time of retirement can be calculated analytically given the utility specification. At the beginning of each period, the household is in one of the three housing positions: inactive renter, active renter and homeowner. After the realization of the income shock, the active renter and the homeowner make their housing tenure choices for the current period and start the next period with their new housing statuses. Let's denote $V_{i}^{r}$ as the value function for a type $i$ active renter after the realization of the income shock and just before the housing choice. Similarly, let $V_{i}^{h}$ be the value function for a type $i$ homeowner and let $V_{i}^{e}$ be the value function for a type $i$ inactive renter. Note that in the current period inactive renter has no housing tenure choice.

Inactive Renter. I start with the problem of an inactive renter. An inactive renter's problem is simple. She does not have any housing tenure choice, she is forced to be a renter in the current period. The only decisions she has to make are the consumption and saving allocations. She starts the next period as an active renter with probability $\delta$ and an inactive renter with probability $(1-\delta)$. Denoting the value function of a type $i$ inactive renter with age $j$, period beginning saving $a$ and income $z$ as $V_{i}^{e}(a, z, j)$, the inactive renter's problem is given by:

$$
V_{i}^{e}(a, z, j)=\max _{c, a^{\prime} \geq 0}\left\{u_{r}(c)+\beta_{i} E\left[\delta V_{i}^{r}\left(a^{\prime}, z^{\prime}, j+1\right)+(1-\delta) V_{i}^{e}\left(a^{\prime}, z^{\prime}, j+1\right)\right]\right\}
$$

subject to

$$
c+a^{\prime}+p_{r}=y(j, z)+a(1+r)
$$

where $c$ is the consumption, $a^{\prime}$ is the next period saving, and $p_{r}$ is the exogenous rental price . Note that the inactive renter derives utility from consumption and being a renter.

Active Renter. Different from an inactive renter, an active renter has to make a housing tenure choice. After the realization of the income shock, an active renter has to decide whether to continue to stay as a renter or purchase a house in the current period. This means I need to define two additional value functions for the active renter. Define $V_{i}^{r r}$ as the value function for a type $i$ active renter who decides to stay as a renter and name such a household as renter. Her problem is very similar to the inactive renter's problem apart from the fact that she starts the next period as an active renter for sure. Given all these facts, I can write the problem of the renter as:

$$
V_{i}^{r r}(a, z, j)=\max _{c, a^{\prime} \geq 0}\left\{u_{r}(c)+\beta_{i} E V_{i}^{r}\left(a^{\prime}, z^{\prime}, j+1\right)\right\}
$$


subject to

$$
c+a^{\prime}+p_{r}=y(j, z)+a(1+r)
$$

The second possible choice of an active renter is to purchase a house.Define the value function for a type $i$ active renter who decides to purchase a house as $V_{i}^{r h}$ and name such a household as purchaser. Housing purchase is done through a mortgage contract. The purchaser, additional to the usual consumption and saving choices, has to choose a mortgage contract. Lenders design the mortgage contracts depending on the observable of the household. Due to the perfect competition in the financial market, lenders make zero-profit on these mortgage contracts. So, only the contracts which make zero-profit are feasible and offered to the household. I denote the set of feasible contracts for a household with observable $\theta$ as $\Upsilon(\theta)$. In the SI economy, $\theta \equiv(a, z, j, i)$ and in the AI economy $\theta \equiv(a, z, j)$. A mortgage contract is specified with a loan amount $d$ and interest rate, $r_{m}$. So, a typical element of the feasible contract set is $\left(d, r_{m}\right) \equiv \ell \in \Upsilon(\theta)$. I leave the construction of $\Upsilon(\theta)$ to the section I define the lender's problem. Since mortgages are due by retirement, which is deterministic, household's age captures the maturity of the mortgage contract. Moreover, since I only focus on fixed payment mortgages, the choice of the loan amount and interest rate, together with the age of the household, determine the amount of mortgage payments, $m$. The calculation of these payments is shown in the lender's problem. Out of the total financial wealth, net of the mortgage payment and downpayment fraction, the household makes her consumption and saving choices and starts the next period as a homeowner. So, I can formulate the problem of the purchaser in the following way:

$$
V_{i}^{r h}(a, z, j)=\max _{\substack{c, a^{\prime} \geq 0 \\\left(d, r_{m}\right) \in \Upsilon(\theta)}}\left\{u_{h}(c)+\beta_{i} E V_{i}^{h}\left(a^{\prime}, z^{\prime}, j+1 ; d^{\prime}, r_{m}\right)\right\}
$$

subject to

$$
\begin{aligned}
c+a^{\prime}+m\left(d, r_{m}, j\right)+p_{h}-d & =y(j, z)+a(1+r) \\
d^{\prime} & =\left(d-m\left(d, r_{m}, j\right)\right)\left(1+r_{m}\right)
\end{aligned}
$$

where $p_{h}$ is the exogenous fixed house price. The household makes the downpayment immediately upon the purchase of the house, or mortgage payments are due by the beginning of each period. Outstanding mortgage debt decumulates according to equation (4). It says that next period outstanding mortgage debt, $d^{\prime}$, is the current period outstanding mortgage debt reduced by the mortgage payment, net of interest payment. Note that since the purchaser becomes a homeowner in the current period, she derives utility from both consumption and being a homeowner.

The value function for the renter together with the value function for the purchaser characterize the value function for the active renter:

$$
V_{i}^{r}=\max \left\{V_{i}^{r r}, V_{i}^{r h}\right\}
$$


Homeowner. A homeowner has three housing choices: stay in the current house, sell the house, or default on the mortgage. This requires us to define three additional value functions. Let $V_{i}^{h h}$ be the value of a type $i$ homeowner who decides to stay in the current house and name such a household as stayer. Apart from the usual state variables $(a, z, j)$, a stayer is also defined by her outstanding mortgage debt, $d$, and interest rate on the mortgage, $r_{m} \sqrt{16}$. A stayer has to make her consumption and saving allocations out of her wealth net of the periodic mortgage payment. The outstanding mortgage debt decumulates according to the same equation I defined in the purchaser's problem. In recursive formulation, the problem of the stayer becomes the following:

$$
V_{i}^{h h}\left(a, z, j ; d, r_{m}\right)=\max _{c, a^{\prime} \geq 0}\left\{u_{h}(c)+\beta_{i} E V_{i}^{h}\left(a^{\prime}, z^{\prime}, j+1 ; d^{\prime}, r_{m}\right)\right\}
$$

subject to

$$
\begin{aligned}
c+a^{\prime}+m\left(d, j, r_{m}\right) & =y(j, z)+a(1+r) \\
d^{\prime} & =\left(d-m\left(d, r_{m}, j\right)\right)\left(1+r_{m}\right)
\end{aligned}
$$

The second possible choice for a homeowner is to sell the house and become a renter, and name such a household as seller. The selling price of the house is exogenously set to $\left(1-\varphi_{h}\right)$ fraction of the purchase price $p_{h}$. This feature tries to capture the possible transaction costs, maintenance costs etc. Moreover, a seller has to pay the outstanding mortgage debt, $d$, in full to the lender. Denoting $V_{i}^{h r}$ as the value function for a type $i$ seller, the recursive formulation of her problem is the following:

$$
V_{i}^{h r}\left(a, z, j ; d, r_{m}\right)=\max _{c, a^{\prime} \geq 0}\left\{u_{r}(c)+\beta_{i} E V_{j+1}^{r}\left(a^{\prime}, z^{\prime}, j+1\right)\right\}
$$

subject to

$$
c+a^{\prime}+p_{r}=y(j, z)+a(1+r)+p_{h}(1-\varphi)-d
$$

Again, since the seller becomes renter in the current period, she pays the rental price and enjoys the utility of a renter.

The third and the last possible choice for a homeowner is to default on the mortgage. Name such a household as defaulter. A defaulter has no obligation to the lender. The lender seizes the house, sells it in the market and pays any positive amount net of the outstanding mortgage debt and selling costs back to the defaulter. For the lender, selling price of the house is assumed to be $\left(1-\varphi_{s}\right) p_{h}$. So, the defaulter receives $\max \left\{\left(1-\varphi_{s}\right) p_{h}, 0\right\}$ from the lender. Defaulter starts the next period as an active renter with probability $\delta$. With $(1-\delta)$ probability she becomes an inactive renter. Denoting $V_{i}^{d}$ as the value function for a type $i$ defaulter, her problem becomes the

\footnotetext{
${ }^{16}$ There are other possible combinations of state variables for the stayer. Since, the mortgage payments are fixed, one can formulate the stayer's problem by using the mortgage payment instead of the outstanding debt. However, it'll be clear in the seller's problem that I also need to know the age of the individual at the time of the origination. To economize from the state variables, I find this formulation more convenient.
} 
following:

$$
V_{i}^{d}(a, z, j)=\max _{c, a^{\prime} \geq 0}\left\{u_{r}(c)+\beta_{i} E\left[\delta V_{i}^{r}\left(a^{\prime}, z^{\prime}, j+1\right)+(1-\delta) V_{i}^{e}\left(a^{\prime}, z^{\prime}, j+1\right)\right]\right\}
$$

subject to

$$
c+a^{\prime}+p_{r}=y(j, z)+a(1+r)+\max \left\{(1-\varphi) p_{h}-d, 0\right\}
$$

Since the defaulter is a renter in the current period, she pays the rental price and enjoys the utility of a renter.

Lastly, I close the decision problem of a homeowner by characterizing her value function, which is the maximum of the above three value functions:

$$
V_{i}^{h}=\max \left\{V_{i}^{h h}, V_{i}^{h r}, V_{i}^{d}\right\}
$$

\subsubsection{Lender's Problem}

Since the mortgages are long-term contracts, the lender's problem is also a dynamic problem. The lender has to design a menu of contracts, $\Upsilon(\theta)$, depending on the observable, $\theta$ of the purchaser. As I mentioned above, a mortgage contract is a combination of a loan amount and an interest rate: $\left(d, r_{m}\right) \in \Upsilon(\theta)$. Note that I do not include mortgage payment, $m$ and maturity as parts of the mortgage contract, because maturity is directly determined through the age of the household, which is observable, and mortgage payment is assumed to be fixed and becomes a function of the loan amount, interest rate and household's age.

Present Value Condition. I first show how the mortgage payments are computed. Since the mortgages are fixed-payment mortgages, the payments are constant through the life of the mortgage. They are directly computed from the present value condition for the contract. This condition says that given the loan amount and the mortgage interest rate, the present discounted value of the mortgage payments should be equal to the loan amount. Since the lender has full commitment on the contract, he calculates the payments as if the contract ends by the maturity. Assuming the interest rate on the mortgage is $r_{m}$ and current age of the household is $j$, this gives me the following formulation for the per-period payments of a mortgage loan with outstanding debt $d$ :

$$
\begin{aligned}
d & =m+\frac{m}{1+r_{m}}+\frac{m}{\left(1+r_{m}\right)^{2}}+\ldots+\frac{m}{\left(1+r_{m}\right)^{J_{r}-j}} \\
m\left(d, r_{m}, j\right) & =\frac{1-\alpha}{1-\alpha^{J_{r}-j+1}} d, \text { where } \alpha=\frac{1}{1+r_{m}}
\end{aligned}
$$


No-Arbitrage Condition. Next, given the mortgage payments and loan amount, the lender has to determine the mortgage interest rate. This rate is pinned down by the no-arbitrage condition. It says that given the expected mortgage payments, the lender should be indifferent between investing in the risk-free market and creating the mortgage loan. Note that the expected payments are not necessarily the above calculated mortgage payments. If the household defaults when the outstanding mortgage debt is $d$, the lender receives $\left.\min \left\{(1-\varphi) p_{h}, d\right\}\right\}^{17}$

Before formulating the no-arbitrage condition, let me denote the value of a mortgage contract with outstanding debt $d$ and interest rate $r_{m}$, offered to a type $i$ household with current period characteristics $(a, z, j)$ as $V_{i}^{\ell}\left(a, z, j ; d, r^{m}\right)$. Note that this function does not only represent the value of the contract at the origination, but also represents the continuation value of the contract at any time period through the mortgage life. Depending on the homeowner's tenure choices, the realized payments may change. If the household stays in the current house, the lender receives the calculated mortgage payment and the continuation value from the contract with the updated characteristics of the household and the loan amount. If the household defaults, then the lender receives $\min \left\{(1-\varphi) p_{h}, d\right\}$. If the household sells the house, the lender receives the outstanding loan amount, $d$.

Given that the opportunity cost of the contract is the risk-free interest rate, $r$, plus the per period transaction cost, $\tau$, and the lender is risk-neutral, the value function for the lender becomes the following:

$$
V_{i}^{\ell}\left(a, z, j ; d, r_{m}\right)=\left\{\begin{array}{cc}
m\left(d, r_{m}, j\right)+\frac{1}{1+r+\tau} E V_{i}^{\ell}\left(a^{\prime}, z^{\prime}, j+1 ; d^{\prime}, r_{m}\right) & \text { if hh stays } \\
\min \left\{p_{h}(1-\varphi), d\right\} & \text { if hh defaults } \\
d & \text { if hh sells }
\end{array}\right\}
$$

where $d^{\prime}=\left(d-m\left(d, r_{m}, j\right)\right)\left(1+r_{m}\right), a^{\prime}$ is the policy function to problems (3) and (6) and finally $m$ is defined by equation 100 .

Now, I am ready to formulate the no-arbitrage condition. At the time of the origination of the contract, the lender may not be able to observe all the characteristics of the household. So, I need to state the no-arbitrage condition conditional on the information structure. It is different for the SI economy and the AI economy.

Symmetric Information: In the SI economy, the lender observes all the characteristics of the household. This actually means mortgage contracts are individualized and independent from all the other households in the economy. The lender can solve the household's problem and obtain the necessary policy functions (saving choice and housing choice) to evaluate the value of the contract at

\footnotetext{
${ }^{17}$ Since default is costly, as long as $p_{h}(1-\varphi) \geq d$, the household sells the house rather than defaulting. This means, in equilibrium, when the household defaults, the lender receives $p_{h}(1-\varphi)<d$ and incurs some loss.
} 
the origination. So, the no-arbitrage condition for a mortgage contract offered to a type $i$ household with characteristics $(a, z, j)$ becomes:

$$
V_{i}^{\ell}\left(a, z, j ; d, r_{m}\right)=d
$$

Note that initial loan amount $d$ is determined by the downpayment fraction: $d=(1-\phi) p_{h}$.

Asymmetric Information: In the AI economy, the lender cannot observe the type of the household, but can observe the other characteristics: $(a, z, j)$. Now, the lender faces a pool of households with the same saving level, income and age, but possibly different types. So, a contract offered to a type is available for the other type in the pool. This creates adverse selection problem. In the appendix, with a simple example, I show that contracts offered in the SI economy may yield negative profits if offered in the AI economy. Specifically, the contract offered to a good type household in the SI economy, is now attractive for a bad type household. The lender cannot differentiate the bad type and good type households, and contract offered to a good type household attracts both types. Since bad type individuals have higher risk of default, this results a loss in the contract designed for the good type household. So, the lender has to either pool different types into a pooling contract or screen different types by offering separating contracts. However, both types of contracts may suffer the problem of not being deviation-free. So, I may not have a Nash-equilibrium. Pooling contracts are always breakable by cream-skimming the good types and separating contracts can also be broken by offering a pooling contract or another separating contract which relies on cross-subsidization if the measure of the good types is sufficiently high. Fortunately, with certain modification in the equilibrium concept or the game structure, it is possible to support the pooling contract as an equilibrium. I leave the discussion of potential problems of existence and other related issues to the appendix, and for now assume the pooling contract is supportable as an equilibrium.

Since a pooling contract attracts both types in the pool, I need to revise the no-arbitrage condition. It should account for the possibility that both types of households have access to this contract. As a result, no-arbitrage condition for a pooling contract becomes the following:

$$
\frac{\sum_{i} V_{i}^{\ell}\left(\theta ; \ell\left(\theta ; d, r_{m}\right)\right) \Gamma_{i}^{r}(\theta)}{\sum_{i} \Gamma_{i}^{r}(\theta)}=d
$$

where $\frac{\Gamma_{i}^{r}(\theta)}{\sum_{i} \Gamma_{i}^{r}(\theta)}$ is the relative measure of each type in the pool of households with observable $\theta \equiv(a, z, j)$. This condition says that at the origination, the expected value of the contract to the lender should be the originated loan amount.

\subsection{Equilibrium}

I begin by defining the equilibrium for the SI economy, and then define the equilibrium for the AI economy. The definition for the SI economy is relatively simple, because in the SI economy markets 
are fully individualized, and the problem of the lender is trivial.

Define the set of state variables for the household as $\Omega$ with a typical element $(a, z, j, i) \sqrt{18}$, and let $\theta \in \Theta \subseteq \Omega$ be the observable characteristics of the household by the lender.

Definition 1 Symmetric Equilibrium: A symmetric equilibrium to the SI economy is a set of policy functions $\left\{c_{s}^{*}, a_{s}^{*}, \ell_{s}^{*}, i_{s}^{*}\right\}$ and a contract set $\Upsilon_{s}$ such that

(i) given the feasible contract set $\Upsilon_{s}, c_{s}^{*}: \Omega \times \Upsilon_{s} \rightarrow \Re, a_{s}^{*}: \Omega \times \Upsilon_{s} \rightarrow \Re$, and $\ell_{s}^{*}: \Omega \times \Upsilon_{s} \rightarrow \Re^{2}$ solve equations (1) - (3) and (6) - (8), $i_{s}^{*}$ is a policy indicator function which solves equations (5) and (9),

(ii) given the policy functions each contract $\ell \in \Omega \times \Upsilon_{s}$ solves equation (12) and

(iii) no lender finds it profitable to offer another contract, which is not in the contract set, $\Omega \times \Upsilon_{s}$, i.e. $\nexists\left(d, r_{m}\right)$ such that $V^{\ell}\left(\theta ; d, r_{m}\right)>d$ for $\forall \theta \in \Theta$, with $V^{\ell}$ defined as in equation (11).

However, in the AI economy, the lender's problem is more complicated. The nature of the equilibrium heavily depends on the type of environment, the definition of equilibrium and the type of equilibrium. I particularly focus on the pooling equilibrium and support the existence of the equilibrium by modifying the equilibrium concept as described in the Appendix. I leave the discussion of all the issues about the existence of equilibrium to the Appendix, and define the equilibrium for the $\mathrm{AI}$ economy in the following way:

Definition 2 Asymmetric Equilibrium - Pooling: An equilibrium to the AI economy is a set of policy functions $\left\{c_{a}^{*}, a_{a}^{*}, \ell_{a}^{*}, i_{a}^{*}\right\}$ and contract set $\Upsilon_{a}$ such that

(i) given the feasible contract set $\Upsilon_{a}, c_{a}^{*}: \Omega \times \Upsilon_{a} \rightarrow \Re, a_{a}^{*}: \Omega \times \Upsilon_{a} \rightarrow \Re$, and $\ell_{a}^{*}: \Omega \times \Upsilon_{a} \rightarrow \Re^{2}$ solve equations (1) - (3) and (6) - (8), $i_{s}^{*}$ is a policy indicator function which solves equations (5) and (9),

(ii) given the policy functions each contract $\ell \in \Omega \times \Upsilon_{a}$ solves equation (13),

(iii) no lender finds it profitable to offer another contract with the anticipation that the other competitors can withdraw their contracts and

(iv) $\Gamma_{i}^{r}$ is consistent with the policy functions.

There are two main differences of the Asymmetric Equilibrium from the Symmetric Equilibrium. The first one is the zero-profit condition. In the AI economy, the equilibrium is pooling whereas it is separating in the SI economy. That is, while the market for each household is individualized in

\footnotetext{
${ }^{18}$ The only relevant household for the lender is the purchaser, since contracts are only offered to them. And the state variable for a purchaser is, as mentioned earlier, $(a, z, j, i)$
} 
the SI economy, the segregation is much less in the AI economy. In the AI economy, since types are not observable, they are pooled and both types receive the same contract. As a result lender has to take the measure of each household into account in the calculation of zero-profit condition.

The second difference is about the equilibrium concept. In the SI economy, I use the well-known and commonly used Nash equilibrium as my equilibrium concept. However, as mentioned in the Appendix, in the AI economy, my environment suffers the problem of existence of equilibrium. So I modify the equilibrium concept following Wilson (1977). This new equilibrium concept is known as Anticipatory Equilibrium and it does notallow deviations of lenders which will be unprofitable upon the other lenders withdraw the initial contracts. Although it is an unusual equilibrium, it has the feature of supporting the pooling contract as an equilibrium. I provide further discussion of this issue in the Appendix. In the next section, I also explore another equilibrium concept, Reactive equilibrium which supports the least-cost separating contract as an equilibrium, and analyze the differences.

Note that the no-arbitrage condition for AI economy, equation (13), specifies a set of mortgage contracts. For each $d \in\left[0, p_{h}\right]$ there is a corresponding $r_{m}$ such that this condition is satisfied. Actually, this set is the pooling iso-profit curve. However, perfect competition requires that the equilibrium should be deviation-free. Although, the new equilibrium concept restricts the set of deviations, in the Appendix I show that the equilibrium with a pooling contract is a unique point. It is the point where the good type household receives the highest utility, i.e. good type household's indifference curve should be tangent to the pooling iso-profit curve. Formally, the equilibrium with pooling contract is characterized by the following equation:

$$
\ell^{*}\left(\theta ; d, r_{m}\right)=\arg \max V_{g}^{r}\left(\theta ; \ell\left(\theta ; d, r_{m}\right)\right)
$$

subject to

$$
d=\frac{\sum_{i} V_{i}^{\ell}\left(\theta ; \ell\left(\theta ; d, r_{m}\right)\right) \Gamma_{i}^{r}(\theta)}{\sum_{i} \Gamma_{i}^{r}(\theta)}
$$

where $\theta \equiv(a, z, j)$ is the observable of the household by the lender.

\section{Findings}

I first present the calibration of the model. Then, I present the results. Lastly, I analyze a counterfactual experiment, and check the robustness of the results to an alternative equilibrium concept. 


\subsection{Calibration}

A set of the parameters is directly taken from the literature. For the rest of the parameters, I calibrate the SI economy to match some relevant data moments for the 2002-2006 period. In particular, I calibrate the utility advantage of homeownership, $\gamma_{h}$, the mortgage servicing $\operatorname{cost} \tau$, and the ratio of discount factors of good type and bad type, $\frac{\beta_{g}}{\beta_{b}}$, to match the homeownership rate, mortgage premium and foreclosure rate in the 2002-2006 period. I first solve the SI economy with these parameters. As I mentioned earlier, the AI economy represents the period before the introduction of automated underwriting systems. Since these systems started to be used by the mid-1990s, I chose the 1991-1995 period representing the AI economy. This period was different from the 2002-2006 period not only in the information structure but also in the house price and risk-free interest rate. So, for the AI economy, I calibrate the rent-price ratio, $\frac{p_{r}^{A I}}{p_{h}^{A I}}$ to match the homeownership rate in the 1991-1995 period using the interest rate and house price in that period. Table 2 presents the results of the calibration.

Table 2: Calibration

\begin{tabular}{clcl}
\hline \hline Parameter & Explanation & Value & Source \\
\hline & & & \\
$\sigma$ & risk aversion & 2 & \\
$\rho$ & persistence of income & 0.84 & literature \\
$\sigma_{\varepsilon}$ & std of innovation to AR $(1)$ & 0.34 & literature \\
$\varphi$ & selling cost & $10 \%$ & \\
$r^{S I}$ & risk-free interest rate & $3.2 \%$ & data \\
$r^{A I}$ & risk-free interest rate & $4.73 \%$ & data \\
$p_{h}^{S I} / \bar{y}$ & price/income ratio & 4.1 & data \\
$p_{h}^{A I} / \bar{y}$ & price/income ratio & 3.1 & data \\
$p_{r}^{S I} / p_{h}^{S I}$ & rent-to-price ratio & $3.1 \%$ & $r^{S I} /(1+r S)$ \\
$\mu_{w}$ & mean of initial wealth/income & -2.794 & GP $(2002)$ \\
$\sigma_{w}$ & std of initial wealth/income & 1.784 & GP $(2002)$ \\
\hline \hline$\beta_{g}$ & discount factor - good & 0.92 & matches wealth-income ratio \\
$\beta_{b}$ & discount factor - bad & 0.84 & matches foreclosure in 2002-2006 \\
$\gamma_{h} / \gamma_{r}$ & utility advantage of ownership & 1.0818 & matches ownership in 2002-2006 \\
$\tau$ & transaction cost of mortgage & $0.46 \%$ & matches premium in 2002-2006 \\
$p_{r}^{A I} / p_{h}^{A I}$ & rent-to-price ratio & 3.49 & matches ownership in 1991-1995 \\
$\delta$ & prob. of being an active renter & 0.17 & matches 5-7 years exclusion \\
\hline \hline
\end{tabular}


Households. A model period is 1 year and households live for 65 periods. The mandatory retirement age is 45 . Utility function for the households is the standard CRRA utility function with a slight modification to account for the benefit of homeownership: $u_{k}(c)=\frac{\left(\gamma_{k} c\right)^{1-\sigma}}{1-\sigma}, k \in\{r, h\}$ and $\gamma_{k}$ is the utility advantage of being a renter $(k=r)$ or homeowner $(k=h)$, I normalize $\gamma_{r}=1$, and calibrate $\gamma_{h}$ to match the homeownership rate in the 2002-2006 period. This implies $\gamma_{h}=1.0818$, which means being a homeowner gives $8.18 \%$ more consumption than being a renter. I set the risk-aversion parameter, $\sigma$, to 2 . I assume the measure of the good types, $\mu$, is $80 \%$. The discount factor for the good type, $\beta_{g}$, is fixed to 0.92 and for the bad type, it is calibrated to match the foreclosure rate in the $2002-2006$ period. This gives me $\beta_{b}=0.84$.

For the income process before retirement, I take the parameters to be consistent with the findings of Hubbard, Skinner and Zeldes (1994), Carroll and Samwick (1997) and Storesletten, Telmer and Yaron (2004). Using their income process, I simulate an economy for a sufficiently long time and estimate the resulting income profile as an $\mathrm{AR}(1)$ process 20 . This gives us the income persistency, $\rho$, as 0.84 and standard deviation of the innovation to the $\operatorname{AR}(1)$ process, $\sigma_{\varepsilon}$, as 0.34 . I approximate this income process with a 15-states first-order Markov process using the discretization method outlined in Adda and Cooper (2003) 21 . For after retirement income, I assume $\lambda=0.35$ and $\eta=0.2$, meaning the retiree receives $35 \%$ of the income at the time of retirement plus $20 \%$ of the mean income in the economy. The probability of becoming an active renter, while the household is an inactive renter, is set to 0.17 , to capture the fact that the bad credit flag stays approximately 5-7 years in the credit history of the household. The loss in the selling price of the house is set to $\varphi=10 \% 2$. The initial distribution of the income is assumed to be the stationary distribution. Following Gourinchas and Parker (2002), the initial distribution of the wealth to income ratio is assumed to be lognormal with mean $\mu_{w / y}=-2.794$ and standard deviation $\sigma_{w / y}=1.784$.

Lenders. The annual risk-free interest rate is set to $r^{S I}=3.2 \%$ for the SI economy, which is the average real return on AAA corporate bond in the 2002-2006 period. The same rate is $4.73 \%$ in

\footnotetext{
${ }^{19}$ Given this utility specification, since there is no housing tenure choice and uncertainty after retirement, I can solve the value function at the time of retirement analytically: $W\left(w_{r}, y_{r}\right)=u_{r}(\bar{c}) \frac{1-\varkappa^{J-J_{r}+1}}{1-\varkappa}$, where $w_{r}$ is the total wealth, including real estate, at the of retirement and $y_{r}$ is the retirement income level, $\bar{c}=\frac{\alpha_{1} y_{r}}{\alpha_{2}}+\frac{w_{r}}{\alpha_{2}}, \alpha_{1}=\frac{1-\omega_{1}^{J-J_{r}+1}}{1-\omega_{1}}$, $\alpha_{2}=\frac{1-\omega_{2}^{J-J_{r}+1}}{1-\omega_{2}}, \omega_{1}=\frac{(\beta(1+r))^{1 / \sigma}}{1+r}, \omega_{2}=\frac{1}{1+r}$, and $\varkappa=\beta(\beta(1+r))^{\frac{1-\sigma}{\sigma}}$.

${ }^{20}$ More specifically, I assume the stochastic component of the log income as a combination of an AR(1) component and transitory component. Within the range of these papers, I assume the persistency of the AR(1) process as 0.96 , the standard deviation of the innovation to the $\mathrm{AR}(1)$ process as 0.16 , and the standard deviation of the transitory shock as 0.22 .

${ }^{21}$ This approximation gives biased results as the persistency of the income process increases. To avoid this bias, I checked the accuracy of the approximation with 15-states Markov process and found that during computation setting $\rho=0.85$ and $\sigma_{\varepsilon}=0.33$ results the desired persistency and standard deviation.

${ }^{22}$ Gruber and Martin (2003) estimates this cost for the homeowner as $7 \%$ using CEX data. Note that I abstract from various other sources of selling the house like house price change, unemployment shock, medical expense shock and I also exclude the depreciation on the houses. So, I think $10 \%$ is a reasonable estimate of the transaction cost for selling the house.
} 
the 1991-1995 period. So, I set the risk-free interest rate in the AI economy to $r^{A I}=4.73 \%$. The annual transaction cost of mortgages to the lender is calibrated to match the mortgage premium in the 2002-2006 period. This gives me $\tau=0.46 \%$ of the loan amount.

Prices. For house prices, I use the metropolitan affordability index from Joint Center for Housing Studies. This index shows the median house price to median household income ratio. The ratio is 4.1 for the 2002-2006 period and 3.1 for the 1991-1995 period. So, I set the ratio of house price to mean income to $\frac{p_{r}^{S I}}{\bar{y}}=4.1$ in the SI economy and $\frac{p_{h}^{A I}}{\bar{y}}=4.1$ in the AI economy. Finally, rent-to-price ratio, $\frac{p_{r}^{S I}}{p_{h}^{S I}}$ is set to $\frac{r^{S I}}{1+r^{S I}}=3.1 \%$ in the SI economy ${ }^{23}$. For the AI economy, I calibrate this ratio to match the homeownership rate in the 1991-1995 period. This gives me $\frac{p_{r}^{A I}}{p_{h}^{A I}}=3.49 \%$

\subsection{Results}

I want to see whether the improvements in information technology - specifically the emergence of automated underwriting systems - can explain the recent changes in the mortgage market, particularly the decrease in the downpayment fraction and the increase in the mortgage premium, foreclosure rate, homeownership rate, loan-to-value ratio, debt-service ratio, and dispersion of mortgage interest rates and downpayment fractions. To pursue this goal, given the above set of parameters, I first solve the SI economy, which is my benchmark economy, and then compare the results to the AI economy. The AI economy represents the period before the introduction of automated underwriting systems, and the SI economy represents the period after the introduction of automated underwriting systems. These two periods not only differ from each other in terms of information structure but also in terms of risk-free interest rate and house price. So, I solve the AI economy with a different set of parameters than the SI economy. Since the transition from the AI economy to the SI economy involves changes in the information structure, risk-free interest rate and house price, it is hard to measure the direct contribution of the information structure on the statistics of interest. To quantify the contribution of the information technology on the mortgage market, I run a counterfactual experiment. In the counterfactual, I focus on the effect of the information structure. I assume that during the transition from the AI economy to the SI economy, the risk-free interest rate and house price have changed to their SI economy counterparts, but the information structure has not changed. That is, I solve the AI economy with the same set of parameters of the SI economy. I define the difference between the results of the SI economy and this counterfactual as the contribution of the change in the information structure24. Lastly, I analyze the results for

\footnotetext{
${ }^{23}$ In the literature the imputed rent is calculated as the sum of cost of foregone interest, cost of property tax, maintenance cost, tax deductability of mortgage interest and expected capital gain. Since I abstract from all other dimensions, the imputed rent in my model corresponds to the cost of foregone interest, which is $\frac{r}{1+r}$.

${ }^{24}$ Since I treat house price as exogenous, it is not exactly the right definition. In a world with endogenous house price, this counterfactual should result lower house price than the house price in the SI economy. So, the actual contribution should be lower than what I define here.
} 
an alternative equilibrium concept, named as Reactive equilibrium. This equilibrium concept can support the least-cost separating contract as an equilibrium. Using Reactive equilibrium, I analyze the first counterfactual and check the robustness of my results to a change in the equilibrium concept.

I first start with the comparison of the AI economy and the SI economy. Table 3 shows the comparison of the two economies as well as how the model matches the data. Overall, the results show that the transition from the AI economy to the SI economy captures the recent trends in the mortgage market. During the calibration, I target the homeownership rate in both economies and the mortgage premium and foreclosure rate in the SI economy. In that perspective, the model matches the data quite well. In the SI economy, the foreclosure rate is $0.44 \%$ and the mortgage premium is $0.52 \%$. The homeownership rate increases from $64.2 \%$ to $68.6 \%$. They are all consistent with their data counterparts.

Table 3: Benchmark Results - Symmetric Information vs Asymmetric Information

\begin{tabular}{|c|c|c|c|c|}
\hline \multirow[b]{2}{*}{ Economy } & \multicolumn{2}{|c|}{ Model } & \multicolumn{2}{|c|}{ Data } \\
\hline & AI & SI & 1991-1995 & 2002-2006 \\
\hline \multicolumn{5}{|l|}{ Statistic } \\
\hline Homeownership rate ${ }^{b}$ & $64.2 \%$ a & $68.6 \%{ }^{\mathrm{a}}$ & $64.2 \%$ & $68.6 \%$ \\
\hline Mortgage premium & $0.49 \%$ & $0.52 \%^{\mathrm{a}}$ & $0.32 \%$ & $0.52 \%$ \\
\hline Foreclosure rate & $0.32 \%$ & $0.44 \%^{\mathrm{a}}$ & $0.33 \%$ & $0.44 \%$ \\
\hline Average downpayment fraction & $27.2 \%$ & $2.9 \%$ & $14.5 \%$ & $8.9 \%$ \\
\hline Coef of variation-downpayment & 0.9 & 4 & 1.28 & 3.55 \\
\hline Coef of variation-int rate & 0.014 & 0.015 & 0.159 & 0.203 \\
\hline Debt-service ratio ${ }^{b}$ & $14.3 \%$ & $20.5 \%$ & $14 \%$ & $15 \%$ \\
\hline Combined loan-to-value ratio ${ }^{b}$ & $52.2 \%$ & $66.4 \%$ & $58.3 \%$ & $67.1 \%$ \\
\hline
\end{tabular}

In the other dimensions, the model does a fairly good job in capturing the trends and levels corresponding to the data. As we switch from the AI economy to the SI economy, the foreclosure rate increases from $0.32 \%$ to $0.44 \%$ while it increases from $0.33 \%$ to $0.44 \%$ in the data. The average downpayment fraction in the model decreases from $27.2 \%$ to $2.9 \%$ while it decreases from $14.5 \%$ to $8.9 \%$ in the data. Coefficient of variation for downpayment fractions increases from 0.9 to 4 and in the data it increases from 1.28 to 3.55. The average combined loan-to-value ratio increases from $52.2 \%$ to $66.4 \%$ whereas in the data the increase is from $58.3 \%$ to $67.1 \%$. The debt-service ratio 
increases from $14 \%$ to $15 \%$ in the data and the model predicts an increase from $14.3 \%$ to $20.5 \%$. The downpayment fraction in the SI economy is below its data counterpart. I think the main reason for this fact is the absence of repeat buyers in my model. Since I abstract from moving shocks and divorce shocks which are the main reasons to buy a house for repeat buyers, and repeat buyers on average put a higher downpayment on the house, my model produces a lower downpayment fraction compared to the data 25 .

One of the main weakness of the model is its deficiency in creating enough mortgage premium and dispersion of mortgage interest rates. Although the model seems to capture the mortgage premium in the 2002-2006 period, it is basically through the high mortgage servicing cost I calibrated to match this moment. The mortgage premium net of the mortgage servicing cost, which is the real premium due to the credit risk of the household, in the SI economy is $0.06 \%$. Similarly, although the coefficient of variation for mortgage interest rate increases - consistent with the data - the levels of the dispersion are far below the values observed in the data. I conjecture that the main reason for this big difference is the absence of several major risk factors that affect households' credit risk. In the model, for a certain type, the credit risk only comes from the income uncertainty. In reality, households face more uncertainty like house price risk, risk-free interest rate risk, medical expense shock, etc. All these factors increase the mortgage premium and also increase the heterogeneity among households which in turn increase the dispersion of interest rates.

Note that the AI economy is different from the SI economy in three dimensions which all have impacts during the transition. Intuitively, a decrease in the risk-free interest rate makes houses more affordable and increases the homeownership rate. Moreover households can afford higher loans meaning the downpayment fraction decreases. However, the effect of interest rate on the loan-to-value ratio and the foreclosure rate is not clear. A decrease in the risk-free interest rate certainly decreases the mortgage interest rate, and as mortgage interest rate decreases the rate outstanding mortgage debt decumulates increases which means combined loan-to-value ratio decreases for the same loan. On the other hand, a decrease in the downpayment fraction increases the combined loan-to-value ratio. So, overall effect is not clear. For the foreclosure rate there are also two opposing effects. As the homeownership rate increases, the mean income of the homeowners decreases since the new home buyers are the lower income households. Further, as the downpayment fraction increases, the credit risk of the household increases and this pushes the foreclosure rate up. However decreasing mortgage interest rate decreases the likelihood of foreclosure. Thus, the net effect depends on the magnitude of these two effects. Similarly, while a decrease in the mortgage payments decreases the debt-service ratio, as low income households purchase houses the mean income of the homeowners decreases and the debt-service ratio increases.

\footnotetext{
${ }^{25}$ A national survey conducted by National Association of Realtors in 2007 reveals that the median downpayment of first-time buyers is just $2 \%$. The same study indicates that the biggest downpayment resource for repeat buyers is the profit they made from their prior house sales. Moreover, I believe that the huge volume of refinancing after 2001 is another important factor to observe high downpayment fraction in the data.
} 
An increase in the house price, on the other hand, makes houses less affordable, decreases the downpayment fraction, increases the loan-to-value ratio and the foreclosure rate.

The effect of a change in the information structure is not trivial, more interesting and the main focus of this paper. I analyze the effect of the information structure in the next section.

\subsection{Counterfactual: The Effect of the Information Structure}

This counterfactual is designed to separate the effect of the information structure. For this purpose, I assume that during the transition from the AI economy to the SI economy, everything changed but the information structure. More specifically, I first solve the SI economy and compare its results to the economy I solve with exactly the same set of parameters but different information structure. I call this economy as the AI-2 economy. The only difference between these two economies is the fact that in the AI-2 economy lenders have partial information about the households whereas in the SI economy they have full information. Column 3 of Table 4 presents the results of this counterfactual. I argue that the change from Column 3 to Column 2 captures the effect of the information structure.

Table 4: Counterfactual-The Effect of the Information Structure

\begin{tabular}{lcccc}
\hline \hline Economy & AI & SI & AI-2 & AI-3 \\
& $\begin{array}{c}r^{A I}, p^{A I} \\
\text { pooling }\end{array}$ & $r^{S I}, p^{S I}$ & $\begin{array}{c}r^{S I}, p^{S I} \\
\text { pooling }\end{array}$ & $\begin{array}{c}r^{S I}, p^{S I} \\
\text { separating }\end{array}$ \\
\hline Statistic & & & & \\
Homeownership rate & $64.2 \%$ & $68.6 \%$ & $68.2 \%$ & $67.3 \%$ \\
Mortgage premium & $0.49 \%$ & $0.52 \%$ & $0.50 \%$ & $0.49 \%$ \\
Foreclosure rate & $0.32 \%$ & $0.44 \%$ & $0.36 \%$ & $0.34 \%$ \\
Average downpayment & $27.2 \%$ & $2.9 \%$ & $4.3 \%$ & $5.4 \%$ \\
CV-downpayment & 0.9 & 4 & 2.9 & 2.5 \\
CV-int rate & 0.014 & 0.015 & 0.01 & 0.014 \\
Debt-service ratio & $14.3 \%$ & $20.5 \%$ & $20 \%$ & $20 \%$ \\
Combined loan-to-value ratio & $52.2 \%$ & $66.4 \%$ & $65.5 \%$ & $64.3 \%$ \\
Welfare Gain & & & $-0.25 \%$ & $-0.29 \%$ \\
\hline \hline
\end{tabular}

All of the results presented in the benchmark calibration qualitatively hold. The homeownership rate, loan-to-value ratio, foreclosure rate, average downpayment fraction, debt-service ratio, and dispersion of interest rate and downpayment have all the same patterns as in the benchmark calibration but in smaller measures. Better information results an increase in the homeownership rate from $68.2 \%$ to $68.6 \%$, the mortgage premium from $0.50 \%$ to $0.52 \%$, the foreclosure rate from 
$0.36 \%$ to $0.44 \%$, the coefficient of variation for mortgage interest rates from 0.01 to 0.015 and for downpayment fractions from 2.9 to 4 , the loan-to-value ratio from $65.5 \%$ to $66.4 \%$, the debt-service ratio from $20 \%$ to $20.5 \%$. Moreover, the downpayment fraction decreases from $4.3 \%$ to $2.9 \%$.

In the SI economy, lenders observe all the characteristics of the household and design contracts for each individual. Figure 1 shows mortgage interest rate as a function of loan-to-value ratio for both types. First of all, it shows a positive relation between the loan-to-value ratio and the mortgage interest rate. As the loan-to-value ratio increases the credit risk of the loan increases and the mortgage premium increases. Secondly, it shows a comparison of the mortgage interest rates for both types. For the same loan amount, good types qualify for a lower mortgage interest rate. Good types have a higher discount factor which makes them care more about the future benefits of the homeownership. As a result they have a lower default probability. This fact decreases the credit risk of the loan and requires a lower mortgage premium.

In the AI-2 economy, lenders cannot observe the types and they face an adverse selection problem. More specifically, if contracts designed in the SI economy are offered, bad types also demand for the contracts designed for the good types and make these contracts carry higher risk of default and yield negative profits. As a result lenders design pooling contracts which give higher utility for the bad type and lower the utility for the good type. Compared to the separating contracts offered in the SI economy, pooling contracts offer higher loan amount and lower mortgage interest rate for the bad types and lower loan amount and higher mortgage interest rate for the good types. Figure 2|(a) shows the comparison of mortgage interest rate as a function of asset level given the same level of loan amount and income for the bad type. Figure 2(b) shows the same figure for the good type. As we switch from AI-2 economy to SI economy, for the same loan amount mortgage premium increases for the bad type while it decreases for the good type. The figures also show that in the SI economy, the dispersion of the mortgage interest rates along the asset dimension is much higher for the bad type, while it is slightly lower for the good type. Figure 2[(c)] and Figure 2[(d)] show the same comparison of both economies along the income dimension. Again, I have similar results in the income dimension. Mean and dispersion of mortgage interest rates increase for the bad type while they decrease for the good type. Overall, the transition from the AI-2 economy to the SI economy makes good types better off and bad types worse off. Moreover, higher premium for the bad type and lower premium for the good type make the loan amount offered to good types to increase while the loan amount offered to the bad types to decrease. Lower utility and higher downpayment fraction crowd some of the bad types who were homeowners in the AI-2 economy out. However, higher utility and higher loan amounts increase the homeownership rate of good types and we see a decrease in the downpayment fraction and an increase in the homeownership rate 26

\footnotetext{
${ }^{26}$ Although bad types are crowded out in the SI economy, the increase in the homeownership rate of the good types dominates and overall homeownership rate increases. The downpayment fraction decreases for the good types, and increases for the bad types. However, some bad types decide not to buy a house upon an increase in the downpayment fraction. Thus, the average downpayment decreases.
} 
Lower downpayment fraction requires higher mortgage premium, and this pushes the mortgage premium up. Lower downpayment fraction together with a higher mortgage premium increase the combined loan-to-value ratio. Note that households who are rationed out in the AI-2 economy but qualify for home purchase in the SI economy are the lower income households. As they enter into the housing market, they lower the average income of the homeowners. This fact, together with an increase in the mortgage payments driven by an increase in the loan-to-value ratio and mortgage premium, increases debt-service ratio. Higher debt-service ratio increases the aggregate risk in the market and we observe an increase in foreclosure rate in the SI economy. Lastly, I calculate the welfare gain due to better information 27. Although, mortgage premium is higher and foreclosure rate is higher in the SI economy, in consumption equivalent terms, the welfare of the household born into the SI economy is $0.25 \%$ higher than the welfare of the household born into the AI- 2 economy. Although bad types' welfare is reduced in the SI economy, the loss is bounded below by quitting to the rental market. However, the welfare of the high types in the SI economy increases without any bound. That's why, overall welfare increases in the economy as information gets better.

I also look at the differences of these two economies over the life-cycle. Figure 3 and Figure 4 show how homeownership rate and foreclosure rate change over the life-cycle in both economies, respectively. Regarding the comparison of the two economies, supporting the aggregate results, homeownership rate and foreclosure rate are both lower in the AI economy compared to the SI economy. Moreover, both economies exhibit hump shape homeownership and foreclosure rates. They are both increasing in the early life-cycle, peak up through the middle age and decrease at the end of the life-cycle. Being a homeowner is more valuable early in the life, because the maturity of the mortgage is longer and the mortgage premium is smaller. However, not all the households can afford to buy a house due to income constraints. Since the income profile is initially increasing and households can save, some households can afford to purchase a house as they age. So, initially we see an increasing pattern in the homeownership rate. But later in the life, income decreases and purchasing a house needs higher amount of payments and larger premiums which decreases the demand for houses. Moreover, through the end of the life-cycle, lower income homeowners sell their houses to smooth consumption and I see a decrease in the homeownership rate.

Foreclosure rate has a similar pattern to the homeownership rate. Note that those who purchase a house in the early periods are the high income households who carry lower risk. As households age, lower income households, who carry higher risk of default, become eligible to purchase a house through saving. So, as households age, the credit risk of the homeowners increases. Moreover, home purchase in later periods requires higher downpayment fraction and mortgage premium, so they carry higher risk of default. Thus, in earlier periods, the credit risk of the average homeowner increases which increases the foreclosure rate. However, as households age, homeowners' home equity increases and lower income households exit the market by selling their houses. Both factors

\footnotetext{
${ }^{27}$ Welfare calculation is in line of Lucas (1987). It is the consumption equivalent gain for the household who is born to the SI economy as opposed to the AI economy.
} 
decrease the probability of default for the homeowners. Hence, late in the life-cycle, foreclosure rate decreases.

Figure 5 shows mean level of income for homeowners and Figure 6 shows mean level of income for renters. Both renters and owners have higher average income in the AI-2 economy. This actually shows that the transition from the AI-2 economy to the SI economy makes houses affordable for lower income households. These are the households that are borrowing-constrained and rationed out in the AI-2 economy. Since, in the AI-2 economy, they are in the upper tail of the income distribution for renters and have lower income than the homeowners, as they become homeowners they decrease the mean income of both renters and homeowners. Secondly, if we compare the income of renters and homeowners, we see that homeowners are richer than the renters.

The reason why we have a decreasing initial trend for homeowner's income over the life-cycle is related to the fact that households purchase a house when they can afford it. Initially only high income households can afford to buy a house, but later, lower income households can afford to buy a house by accumulating assets. So, over the life cycle, the pool of the homeowners start to include lower income households and the average income of the pool decreases despite the increase in the mean income due to the hump-shape profile of the income over the life-cycle. Although the hump-shape profile suggest the income to decrease through the end of the life-cycle, we observe an increase in the homeowner's income close to the end of the life-cycle. This is related to the usual consumption smoothing argument. Households enjoy utility at the last period by selling the house. Risk averse households, especially the ones with lower income, sell their houses at earlier periods to smooth their consumption. As a result, through the end of the life-cycle we see the lower income households selling their houses and increasing the average income of the homeowners.

For the renters, we see a similar profile of the mean income over the life-cycle. Initially the mean income decreases as the households at the upper tail of income distribution for renters purchase houses and become homeowners. Later, the increase due to the hump shape of income profile dominates and mean income starts to increase. The rapid increase through the end of life cycle is again due to the households who sell their houses to smooth their consumption.

Figure 7 shows the debt-to-income ratio over the life cycle in both economies. The ratio is strictly smaller in the AI-2 economy compared to the SI economy over the life cycle. In both economies the ratio has an increase in the early periods for a short time followed by a monotonic decrease till the end of the life-cycle. In the earlier years, households with higher income prospects purchase a house. But, as households age we see those households with lower income prospects purchase houses. So, we observe an increase in the debt-to-income ratio initially. However, as households age, the mortgage debt decumulates, and lower income homeowners quit housing either by selling or defaulting. Thus, later in the life-cycle, we observe a decrease in the debt-to-income ratio.

Figure 8 shows the debt-service ratio over the life cycle. The ratio increases over the life-cycle. In the initial periods, lower income households enter to homeownership and as Figure 5 shows we 
observe a decrease in mean income of homeowners despite the increasing income profile due to life-cycle hump-shape. The later entrants of homeonwership are the lower income households and they face higher mortgage payments, because they face higher premium and the maturity of the mortgages is shorter. Thus, since average mortgage payment increases and mean income decreases, we observe an increase in the debt-service ratio. Through the end of the life-cycle, the hump-shape profile of income forces the debt-service ratio to increase. If we compare the ratio across the two economies we observe a higher ratio in the SI economy compared to the AI economy. This is because of two facts. Compared to the AI economy, in the SI economy the mean income of the homeowners is lower and secondly households face higher mortgage premium and lower downpayment fraction, which both increase the mortgage payment. Lower mean income and higher mortgage payments increase the debt-service ratio and we observe a higher debt-service ratio in the SI economy.

Lastly, Figure 9 presents the consumption path for the homeowner and Figure 10 shows the consumption path for the renter over the life-cycle in both economies 28 . Both the homeowners and the renters have increasing consumption path over the life cycle. The initial increase in the consumption is due to the increasing pattern of the income process in the early life-cycle. However, contrary to what we observe in the data, later in the life-cycle consumption continues to increase. This is due to the huge consumption jump through the end of the life-cycle driven by selling the house. When we compare both economies in terms of consumption paths, we see a very similar pattern in the SI and the AI-2 economies. Both homeowners and renters have higher consumption in the AI-2 economy. We know that in the SI economy, good type households with lower income prospects who are rationed out in the AI-2 economy face better mortgage contract terms. These households are the marginal households and they have better income prospects with respect to the ones in the pool of the renters. As we switch from the AI-2 economy to the SI economy, they become homeowners and we observe a decrease in the income level of the renters. This is the main reason for the lower consumption in the SI economy for the renters. For the homeowners, the logic is similar. In the SI economy, they have lower consumption because of two reasons. On the one hand lower income households join to the pool of the homeowners. This transition decreases the average income of the homeowners, which in turn decreases the average consumption of the homeowners. On the other hand, in the SI economy the average debt-service ratio is higher mainly due to the higher loans and higher mortgage premiums. This clearly increases the financial burden on the households and decreases their consumption.

\subsection{Alternative Equilibrium Concept}

As I mentioned earlier, the existence of Nash equilibrium is hard to justify in the current environment. That's why, I changed the equilibrium concept slightly and support the pooling contract as an equilibrium. In the literature, there is also another equilibrium concept proposed to overcome

\footnotetext{
${ }^{28}$ The consumption levels are in terms of the mean income.
} 
the problem of existence in these types of screening models. It is introduced by Riley (1979) and known as Reactive Equilibrium. Different than the Nash equilibrium and Anticipatory equilibrium it assumes that the lenders can react to a deviation by adding new contracts. So, deviations which would be unprofitable after the other lenders add new contracts are not allowed. This equilibrium concept has the feature of supporting the least-cost separating contract as an equilibrium.

A separating contract should satisfy two properties. First, it should yield zero-profit to the lender given that the targeted type takes the contract. Second it should be incentive compatible for the targeted household. This last property says that the contract designed for the other type in the same pool should not give a higher utility to the targeted household. Formally I can write the no arbitrage condition in the following way:

$$
V_{i}^{\ell}\left(\theta ; \ell_{i}\left(\theta ; d, r_{m}\right)\right)=d
$$

subject to

$$
V_{i}^{r}\left(\theta ; \ell_{i}\left(\theta ; d, r_{m}\right)\right) \geq V_{i}^{r}\left(\theta ; \ell_{i^{\prime}}\left(\theta ; d^{\prime}, r_{m}^{\prime}\right)\right), \forall i^{\prime} \text { such that } \Gamma_{i^{\prime}}^{r}(\theta)>0
$$

where $\ell_{i}\left(\theta ; d, r_{m}\right) \equiv\left(d, r_{m}\right)$ is the contract designed for type $i$ household with observable $\theta \equiv(a, z, j)$ and $\Gamma_{i}^{r}(\theta)$ is the distribution of type $i$ renters with observable $\theta$ and lastly $d=(1-\phi) p_{h}$.

Definition 3 Asymmetric Equilibrium - Separating: An asymmetric separating equilibrium to the AI economy is a set of policy functions $\left\{c_{a}^{*}, a_{a}^{*}, \ell_{a}^{*}, i_{a}^{*}\right\}$ and contract set $\Upsilon_{a}$ such that

(i) given the feasible contract set $\Upsilon_{a}, c_{a}^{*}: \Omega \times \Upsilon_{a} \rightarrow \Re, a_{a}^{*}: \Omega \times \Upsilon_{a} \rightarrow \Re$, and $\ell_{a}^{*}: \Omega \times \Upsilon_{a} \rightarrow \Re^{2}$ solve equations (1) - (3) and (6) - (8), $i_{s}^{*}$ is a policy indicator function which solves equations (5) and (9),

(ii) given the policy functions each contract $\ell \in \Omega \times \Upsilon_{a}$ solves equation (15),

(iii) no lender finds it profitable to offer another contract even after the other competitors can react by adding new contracts and

(iv) $\Gamma_{i}^{r}$ is consistent with the policy functions.

There are two main differences of the Asymmetric Separating Equilibrium than the Symmetric Equilibrium. The first one is the zero-profit condition. In the AI economy, the equilibrium is separating as it is in the SI economy. That is, the market for each household is individualized. However, in the AI economy, the lender has to take into account all the incentive compatibility constraints which are summarized by equation (15). It says that each type picks the contract designed for her and the contract designed for the other type with the same observable yields no better utility. This constraint puts extra restriction on the equilibrium contracts compared to the ones offered in the SI economy. In general, good types qualify for "better" terms compared to the bad types since bad types carry higher risk of default. So, bad types have always incentive to 
take the contracts designed for the good types if only the equilibrium contracts in the SI economy are offered. This forces the good types differentiate themselves from the bad types. In my model they differentiate themselves using the downpayment fraction. Good types demand for lower loans which are not attractive for bad types. However, these loans give lower utility for the good types compared to the SI equilibrium contracts, which means it is costly for good types to differentiate themselves.

The equilibrium contract in the AI economy has the following feature. The bad type in a pool receives the contract offered to her in the SI economy and good type receives the contract such that the bad type is indifferent between the contract offered to her and this contract. This equilibrium contract is called the least-cost separating contract, because it is the contract in which good types differentiate themselves with the minimum cost.

The second difference is about the equilibrium concept. In the SI economy, I use the well-known and commonly used Nash equilibrium as my equilibrium concept. However, as mentioned in the Appendix, in the AI economy, my environment suffers the problem of existence of equilibrium. So, I modify the equilibrium concept as in the lines of Riley (1979), which is called Reactive Equilibrium. This equilibrium concept does not allow deviations of lenders which will be unprofitable upon the other lenders react by adding new contracts. Although it is an unusual equilibrium, it has the feature of supporting the least-cost separating contract as an equilibrium. I provide further discussion of this issue in the Appendix.

Using the Reactive equilibrium concept, I solve the model with the benchmark calibration. Column 4 of Table 4 presents the results for the new equilibrium. The results show that the changes are similar. Homeownership rate, loan-to-value ratio, foreclosure rate, debt-service ratio, mortgage premium and dispersion of mortgage interest rate are all very similar compared to the economy with the pooling contract as an equilibrium. As a welfare comparison, the results show that better information increases the welfare of the households by $0.29 \%$ in consumption equivalent terms.

\section{Conclusion}

In this paper I have explored the effect of technological improvements on the mortgage market. I show that, thanks to the automated underwriting systems, as lenders can better assess the credit risk of the households the market experiences a decrease in the downpayment fraction and consequently an increase in the homeownership rate, loan-to-value ratio, foreclosure rate, and dispersion of mortgage interest rates, which are all consistent with the recent trends in the data. I have also shown that the removal of informational asymmetry between lenders and households makes the households better off.

My quantitative work sheds some light on how the mortgage market responds to a change in 
the supply of credit and it has the potential to answer the implications of different policies directed to the mortgage market. However taking the house prices in the model exogenous masks the real effects of these policies. Understanding how house prices respond to the changes in the market seems to be important to fully capture the real effects of different policies. The extension of the current framework with endogenous house prices is an ambitious but necessary step forward.

Moreover, recent financial crisis stemmed from the subprime mortgage market has brought a lot of attention to how the mortgage market operates. Although my framework is useful to understand the interaction between lenders and households, it is mute in the interaction of lenders and investors which I think is the real cause of the current crisis. So, as a next step it is important to model the interaction between lenders and investors, in which there is significant informational asymmetry.

\section{A Existence of Equilibrium - A Simplified Model}

To better address the issues involved with the existence of the equilibrium, I now modify the model to a simpler version. Assume that there are only two periods, there is no saving and households are risk-neutral. Households are hand-to-mouth agents. I abstract from the first period choice problem, because the issues involved with the existence of equilibrium are relevant for the households who are offered contracts. So, in the first period, I assume that households are all purchasers. Income follows random walk: $\theta_{t}=\theta_{t-1}+\varepsilon$, where $\varepsilon$ is mean-zero normal random variable with variance

$\sigma_{\varepsilon}^{2}$. In the second period, after realizing the income shock, homeowner can either stay in the current house, then she has to make her mortgage payments and she enjoys the utility from being a homeowner, and in the final period she receives income from selling the house. If she defaults, she becomes a renter and enjoys the utility of being a renter: there is no other cost of default and no rental price. Suppose there is no selling option. From the same consumption, homeowners get $\gamma>1$ times higher utility than the renter. I skip the problem of a renter in the second period, because I assume that she has no housing option in the second period. She basically has to stay as a renter. Moreover, set the price of a house to $p_{h}=1$.

Using equation (10), I get mortgage payment to be $m=\frac{1+r_{m}}{2+r_{m}}$ when the mortgage interest rate is $r_{m}$. The last period utility of a type $i$ stayer becomes $u_{2}^{h h}\left(\theta, i ; d, r_{m}\right)=\gamma(\theta-m d)+\beta_{i}$. Similarly, the utility of a defaulter becomes $u_{2}^{d}(\theta, i)=\theta$. Since the second-period beginning utility of a homeowner is $u_{2}^{h}\left(\theta, i ; d, r_{m}\right)=\max \left\{u_{2}^{h h}\left(\theta, i ; d, r_{m}\right), u_{2}^{d}(\theta, i)\right\}$, I get

$$
u_{2}^{h}\left(\theta, i ; d, r_{m}\right)=\left\{\begin{array}{cc}
\gamma(\theta-m d)+\beta_{i} & \text { if } \theta \geq \theta_{i}^{*} \\
\theta & \text { if } \theta<\theta_{i}^{*}
\end{array}\right\}
$$

where $\theta_{i}^{*}=\frac{\gamma m d-\beta_{i}}{\gamma-1}$. 
Then first period utility of a purchaser becomes the following:

$$
\begin{aligned}
u_{1}^{r h}(\theta, i) & =\max _{\left(d, r_{m}\right) \in \Upsilon(\theta)}\left\{u\left(\theta, i ; d, r_{m}\right)\right\} \quad \text { where } \\
u\left(\theta, i ; d, r_{m}\right) & =\gamma(\theta-m d-(1-d))+\beta_{i} \int^{\theta_{i}^{*}-\theta}(\theta+\varepsilon) d F(\varepsilon)+\beta_{i} \int_{\theta_{i}^{*}-\theta}\left[\gamma(\theta+\varepsilon-m d)+\beta_{i}\right] d F(\varepsilon) \\
& =\gamma d\left(1-m\left(1+\beta_{i}\left(1-F\left(\theta_{i}^{*}-\theta\right)\right)\right)+\kappa_{i}\left(\theta, \theta^{*}\right) \quad\right. \text { where } \\
\kappa_{i}\left(\theta, \theta_{i}^{*}\right) & =\gamma(\theta-1)+\beta_{i} \int^{\theta_{i}^{*}-\theta}(\theta+\varepsilon) d F(\varepsilon)+\beta_{i} \int_{\theta_{i}^{*}-\theta}\left(\gamma(\theta+\varepsilon)+\beta_{i}\right) d F(\varepsilon)
\end{aligned}
$$

Similarly, the value of a mortgage contract $\left(d, r_{m}\right)$ offered to type $\theta$ household becomes:

$$
\begin{aligned}
v\left(d, r_{m} ; \theta, i\right) & =m d+\frac{1}{1+r} \int_{\theta_{i}^{*}-\theta} \operatorname{mdd} F(\varepsilon) \\
& =m d\left(1+\frac{1}{1+r}\left(1-F\left(\theta_{i}^{*}-\theta\right)\right)\right)
\end{aligned}
$$

Then no-arbitrage condition simply implies that the profit to the lender is equal to zero:

$$
\begin{aligned}
\pi\left(d, r_{m} ; \theta\right) & =m d\left(1+\frac{1}{1+r}\left(1-F\left(\theta_{i}^{*}-\theta\right)\right)\right)-d \\
m & =\frac{1}{1+\frac{1}{1+r}\left(1-F\left(\theta_{i}^{*}-\theta\right)\right)} \in\left[\frac{1+r}{2+r}, 1\right)
\end{aligned}
$$

I now illustrate the equilibrium to the above economy in a phase-diagram of contract space: $\left(d, r_{m}\right)$. Using equations (16) and (17), I can construct the indifference curve and the iso-profit curve for the household. Figure 11](a) shows typical indifference curves. For a good type, it is denoted by $u\left(\theta_{H}\right)$, and for a bad type, it is denoted by $u\left(\theta_{L}\right)$. The iso-profit curve, for a good type, is denoted by $\pi\left(\theta_{H}\right)$, and for a bad type it is denoted by $\pi\left(\theta_{L}\right)$. The indifference curves yield higher utility as they shift to the right, so the equilibrium to the symmetric information economy is the point where the indifference curve is tangent to the iso-profit curve for each type. So, $\left(d_{L}^{*}, r_{L}^{*}\right)$ and $\left(d_{H}^{*}, r_{H}^{*}\right)$ are the equilibrium to the SI economy.

Problem of Existence of Nash equilibrium . In the asymmetric information economy, the types are not observable. So, both contracts are available for the households. Clearly, the contract designed for the good type gives a higher utility for the bad type. If both contracts are offered, both types choose the contract $\left(d_{H}^{*}, r_{H}^{*}\right)$ and the lender makes negative profit. So, the equilibrium in the SI economy is not sustainable in the AI economy. In the literature two types of contracts are suggested as a potential equilibrium to the AI economy facing the adverse selection problem: pooling contracts and separating contracts. A pooling contract pools both types into a single contract, while a separating contract is able to separate the types. As it is analyzed in 
Rothschild and Stiglitz (1976), a pooling contract cannot be a Nash equilibrium to the AI economy. The intuition is simple. As it is seen in Figure 11/(b), point $E_{p}$ is a candidate pooling equilibrium. It is on the iso-profit curve for the pool. However, a point in the dotted region, like point $\tilde{E}$ creamskims only the good types and since it is on the left of the iso-profit curve for the good type, it yields a positive profit to the lender. So, such a deviation is profitable for the lender which results a pooling contract not to be an equilibrium contract. Although it is not guaranteed, a separating equilibrium may exist. Figure 11|(c) shows a candidate separating equilibrium. Such a separating contract is called least-cost separating contract. Contracts $E_{H}^{S}$ and $E_{L}^{S}$ separate both types. Either type finds it not optimal to choose the contract designed for the other type and both contracts make zero-profit. Since the iso-profit curve for the pool is to the left of the indifference curve for the good type, good types never prefer a pooling contract. So, pooling contracts cannot break the separating equilibrium. However, if the proportion of the good types is sufficiently high, then it is possible to break the candidate separating equilibrium by either a pooling contract or another separating contract which relies on cross-subsidization. Figure 11)(d) shows how a pooling contract breaks the separating equilibrium. Any point in the shaded region is a profitable deviation for the lender. It attracts both types and yields a positive profit. In such an environment no Nash equilibrium exists. Note that the least-cost separating contract can only be broken by contracts which rely on cross-subsidization. However, such contracts can always be broken with a separating contract which cream-skims only the good types.

Anticipatory Equilibrium. It is possible to support a pooling contract by modifying the equilibrium concept as in Wilson (1977). He proposes the anticipatory equilibrium concept, where any deviation which would become unprofitable if the initial contracts are withdrawn are not allowed. Note that a pooling contract is not a Nash equilibrium, because it can broken by creamskimming the good types as it is seen in Figure 11)(b). However, such a deviation will be unprofitable if the others can withdraw their contracts. In the current example, it means that a deviation like point $\tilde{E}$ in Figure 11(b) becomes unprofitable if the initial contract $E_{p}$ is withdrawn. Because it'll attract both types and results a negative profit. So, such deviations do not threat the equilibrium and the pooling contract survives as an equilibrium.

A pooling contract attracts both types, so the no-arbitrage condition should account for this fact. Any point on $\pi(\bar{\theta})$ in Figure 11 (b) is a candidate for equilibrium. However, the equilibrium should be deviation-free, where the set of deviations is restricted by the new equilibrium concept. The condition for the equilibrium to be deviation-free further restricts the equilibrium to a unique point at which the good type receives the maximum utility, i.e. it is the point where the indifference curve for the good type is tangent to the pooling iso-profit curve. Other pooling contracts where the good type receives lower utility are not equilibrium, because such a contract can be easily broken by offering a contract which gives slightly higher utility for the good type and lower utility for the low type but still above the pooling iso-profit curve. 
At this point, it is also worthwhile to mention that this equilibrium can also be supported as a perfect Bayesian equilibrium of a modified game. Hellwig (1987) modifies the game in these types of screening games and shows that the above defined pooling contract is the unique stable perfect Bayesian equilibrium of the modified game. The modification is the follows. Suppose in the first stage, as in the original game, lenders offer contracts. However before households choose from these contracts, different than the original game, Hellwig introduces a second stage where the lenders can see the other lenders' contracts and are allowed to withdraw their contracts. Finally in the third stage, households choose from the remaining contracts and contracts are executed. This game is clearly in the spirit of the Wilson's Anticipatory equilibrium concept and supports the pooling contract as equilibrium contract.

Reactive Equilibrium. Riley (1979) offers another equilibrium concept, Reactive Equilibrium, so that the least-cost separating contract survives as an equilibrium. The only difference of the Reactive equilibrium from the Nash equilibrium is that it does not allow any deviations that would become unprofitable if they led the other lenders to react by adding new contracts. Note that the least-cost separating contract can only be broken by a contract which depends on cross-subsidization. Any contract with cross-subsidization can be broken with another separating contract by cream-skimming the good types and yields the lender offering such a contract only the low types and consequently negative profit.

Here, it is useful to mention that it is also possible to model the above economy as a signalling game rather than a screening game. In signalling games, the uninformed player moves first. In my economy, it corresponds to the following game. In stage one, households move and choose a loan amount. After observing the loan amount and other characteristics of the household, in the next and last stage, lenders compete by offering mortgage interest rate. The last stage of the game, due to perfect competition, is simple. Basically, lenders set the zero-profit mortgage interest rate corresponding to the observable and loan amount. In the signalling games, I have to deal with the beliefs. In my environment, the households can signal their types by choosing the loan amount. Then the lenders have to form their beliefs on the type of the households based on this signal. The common equilibrium concept used in the literature is the perfect Bayesian equilibrium. Wherever possible, the beliefs are formed using the household's strategies in a bayesian fashion. However, the lenders also have to assign beliefs for off-the-equilibrium strategies. This feature of the model gives potential multiplicity of the equilibria. It is possible to have a continuum of pooling and separating equilibria. Nevertheless, using the equilibrium refinements, specifically intuitive criterion, introduced in Cho and Kreps (1987), and universal divinity, introduced in Banks and Sobel (1987), the unique outcome of the game becomes the least-cost separating equilibrium. 


\section{References}

[1] Adda, J., and R. Cooper (2003): Dynamic Economics. MIT Press, Cambridge, Massachusetts.

[2] Athreya, K. (2002): "Welfare implications of the Bankrupcy Reform Act of 1999," Journal of Monetary Economics, 49, 1567-1595.

[3] Athreya, K. (2004): "Shame as it Ever Was: Stigma and Personal Bankruptcy," Federal Reserve Bank of Richmond Economic Quarterly, 90(2), 1-19.

[4] Athreya, K. X. Tam and E. Young (2008): "A Quantitative Theory of Information and Unsecured Credit," working paper.

[5] Banks, J. and J. Sobel (1987): "Equilibrium Selection in Signaling Games," Econometrica, 55, 647-62.

[6] Barakova, I., R. Bostic, P. Calem, and S. Wachter (2003): "Does Credit Quality Matter for Ownership?," Journal of Housing Economics, 12(4), 318-336.

[7] Bolton, P. and M. Dewatripont (2005): Contract Theory, MIT Press, Cambridge, Massachusetts.

[8] Carroll, C., and A. Samwick (1997): "The Nature of Precautionary Wealth," Journal of Monetary Economics, 40(4), 41-71.

[9] Chambers, M. S., C. Garriga and D. Schlagenhauf (2008): "Accounting for Changes in the Homeownership Rate," International Economics Review, forthcoming.

[10] Chatterjee, S., D. Corbae, M. Nakajima, and J. V. Rios-Rull (2007): "A Quantitative Theory of Unsecured Consumer Credit with Risk of Default," Econometrica, 75(6), 1525-1591.

[11] Chatterjee, S., D. Corbae, and J. V. Rios-Rull (2007): "A Finite-Life Private-Information Theory of Unsecured Consumer Debt," Journal of Economic Theory, forthcoming.

[12] Chatterjee, S., D. Corbae, and J. V. Rios-Rull (2008): "Credit Scoring and the Competitive Pricing of Default Risk," Working paper, University of Texas at Austin.

[13] Cho, I-K. and D. M. Kreps (1987): "Signaling Games and Stable Equlibria," Quarterly Journal of Economics, 102, 179-221.

[14] Cutts, A. M., R. K. Green (2004): "Innovative Servicing Technology: Smart Enough to Keep People in Their Houses?", working paper, Freddie Mac.

[15] Doms, M. and J. Krainer (2007): "Innovations in Mortgage Markets and Increased Spending on Housing," Working paper, Federal Reserve Bank of San Francisco. 
[16] Gates, S., V. Perry and P. Zorn (2002): "Automated Underwriting and Lending Outcomes: The Effect of Improved Mortgage Risk Assessment on Under-served Populations", working paper.

[17] Gerardi, K., H. Rosen, and P. Willen (2006): "Do Households Benefit from Financial Deregulation and Innovation? The Case of the Mortgage Market," working paper.

[18] Gourinchas, P.-O., and J. Parker (2002): "Consumption over the Life Cycle," Econometrica, $70(1), 47-89$.

[19] Hellwig, M. (1987): "Some Recent Developments in the Theory of Competition in Markets with Adverse Selection," European Economic Review, 31, 319-325.

[20] Hubbard, R., J. Skinner, and S. P. Zeldes (1994): "The Importance of Precautionary Motives in Explaining Individual and Aggregate Saving," Carnegie-Rochester Conference Series on Public Policy, 40, 59-125.

[21] Hunt, R. M. (2005): "A Century of Consumer Credit Reporting in America," working paper, Federal Reserve Bank of Philadelphia.

[22] LaCour-Little, M. (2000): "The Evolving Role of Technology in Mortgage Finance," Journal of Housing Research, 11(2), 173-205.

[23] Livshits, I., J. MacGee, and M. Tertilt (2007a): "Accounting for the Rise in Consumer Bankruptcies," NBER Working Paper No. 13363.

[24] Livshits, I., J. MacGee, and M. Tertilt (2007b): "Consumer Bankruptcy: A Fresh Start," The American Economic Review, 97(1), 402-418.

[25] Livshits, I., J. MacGee, and M. Tertilt (2008): "Costly Contracts and Consumer Credit," working paper.

[26] Lucas, R. (1987): Models of Business Cycles, Oxford: Basil Blackwell.

[27] Mian, A., and A. Sufi (2008): "The Consequences of Mortgage Credit Expansion: Evidence from the 2007 Mortgage Default Crisis," NBER Working Paper No. 13936.

[28] Narajabad, B. N. (2007): "Information Technology and the Rise of Household Bankruptcy," Working paper, Rice University.

[29] Ortalo-Magne, F., and Rady (2006): "Housing Market Dynamics: On the Contribution of Income Shocks and Credit Constraints," Review of Economic Studies, Vol. 78, pp. 459-485.

[30] Pafenberg, F. (2004): "The Single-Family Mortgage Industry in the Internet Era: Technology Developments and Market Structure", working paper, OFHEO. 
[31] Pennington-Cross, A. (2003): "Credit History and the Performance of Prime and Nonprime Mortgages," The Journal of Real Estate Finance and Economics, vol. 27(3), 279-301.

[32] Piskorski, T., and A. Tchistyi (2007): "Optimal Mortgage Design," working paper, NYU.

[33] Riley, J. (1979) : "Informational Equilibrium," Econometrica, 47(2), 331-359.

[34] Rothschild, M., and J. Stiglitz (1976): "Equilibrium in Competitive Insurance Markets: An Essay on the Economics of Imperfect Information," The Quarterly Journal of Economics, 90(4), 629-649.

[35] Sanchez, J. M. (2008): "The Role of Information in Consumer Debt and Bankruptcy," working paper.

[36] Storesletten, K., C. Telmer, and A. Yaron (2004): "Consumption and Risk Sharing over the Life Cycle," Journal of Monetary Economics, 51, 609-633.

[37] Straka, J. W. (2000): "A Shift in the Mortgage Landscape: The 1990s Move to Automated Credit Evaluations," Journal of Housing Research, 11(2), 207-232.

[38] Tracy, J. and H. Schneider (2001): "Stocks in the Household Portfolio: A Look Back at the 1990's", Current Issues in Economics and Finance 7(4), Federal Reserve Bank of New York.

[39] Wilson, C. (1977): "A Model of Insurance Markets with Incomplete Information," Journal of Economic Theory, 16, 167-207. 
Figure 1: Mortgage Interest Rate as a Function of Loan Amount

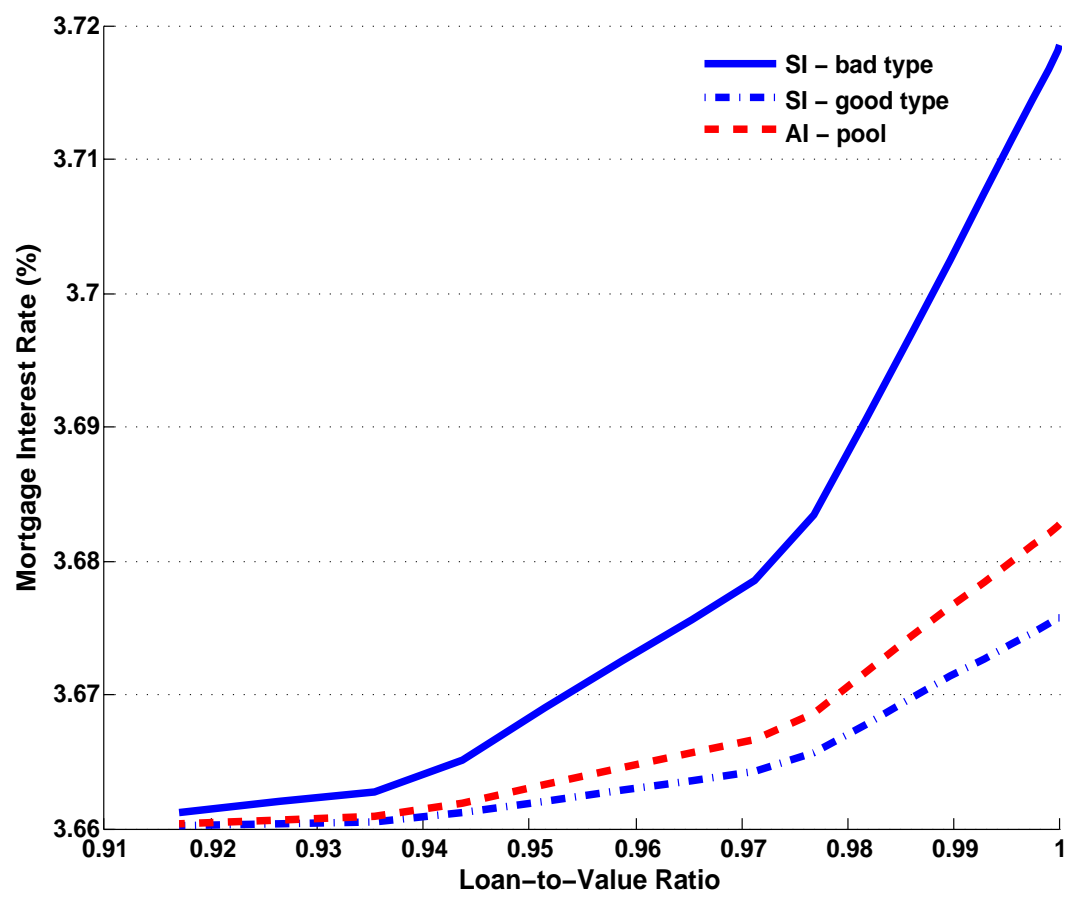


Figure 2: Mortgage Interest Rate in Both Economies

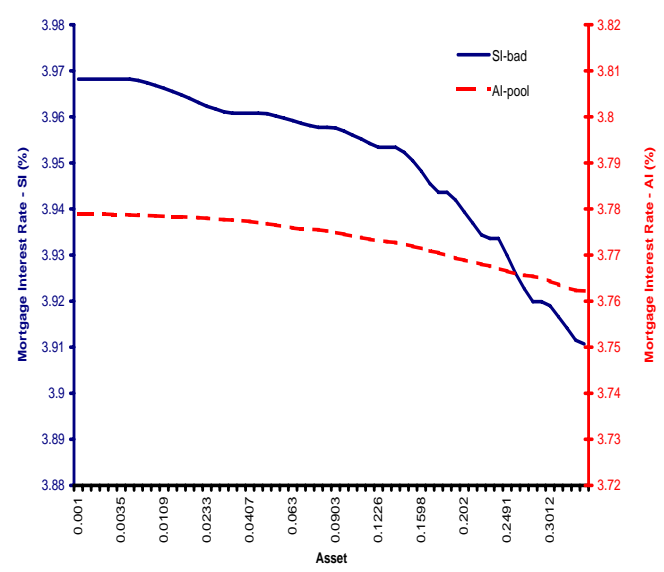

(a) Comparison for Bad Type - Asset Dimension

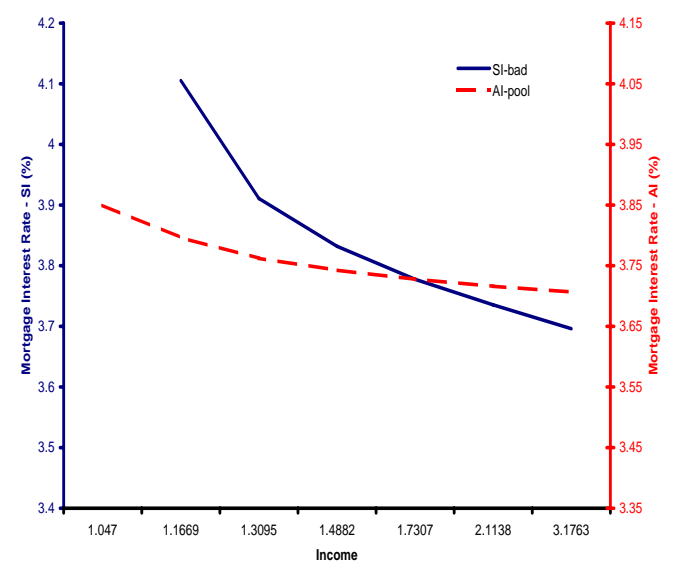

(c) Comparison for Bad Type - Income Dimension

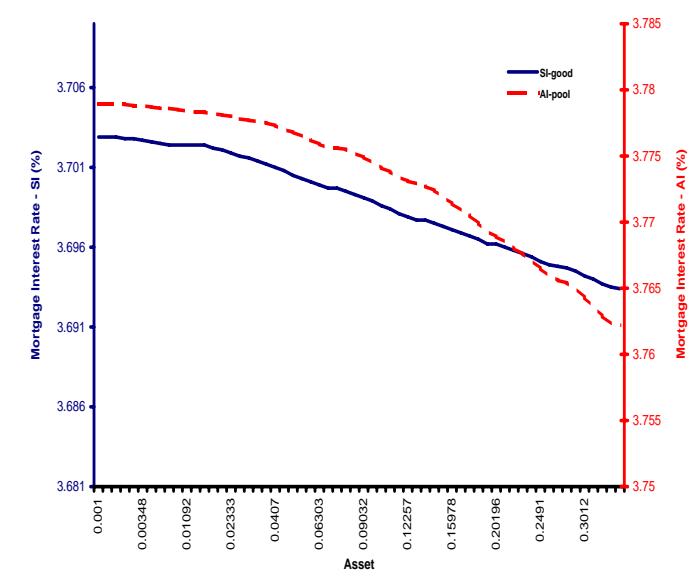

(b) Comparison for Good Type - Asset Dimension

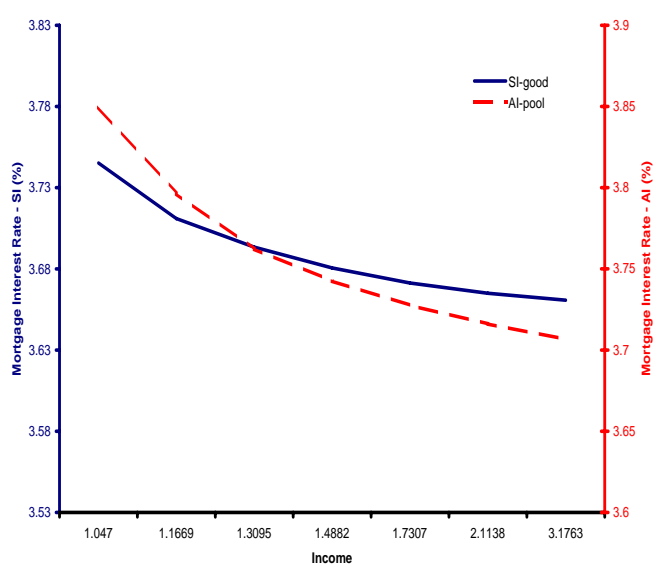

(d) Comparison for Good Type - Income Dimension 
Figure 3: Homeownership Rate over the Life Cycle in SI vs AI

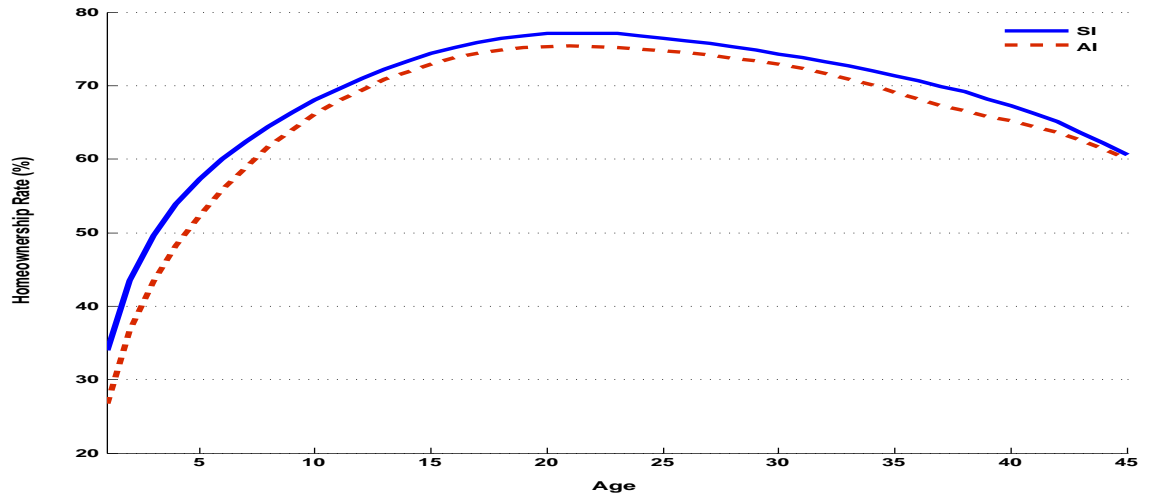

Figure 4: Foreclosure Rate over the Life Cycle in SI vs AI

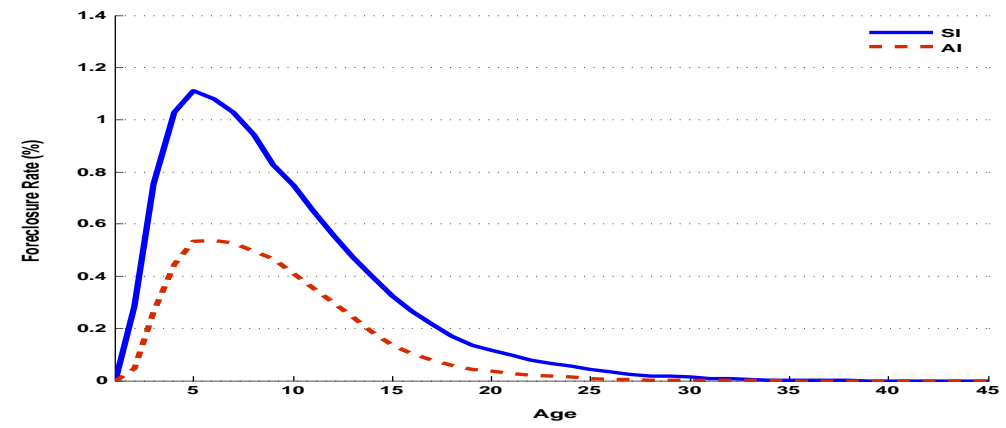


Figure 5: Mean Income of Homeowner over the Life Cycle in SI vs AI

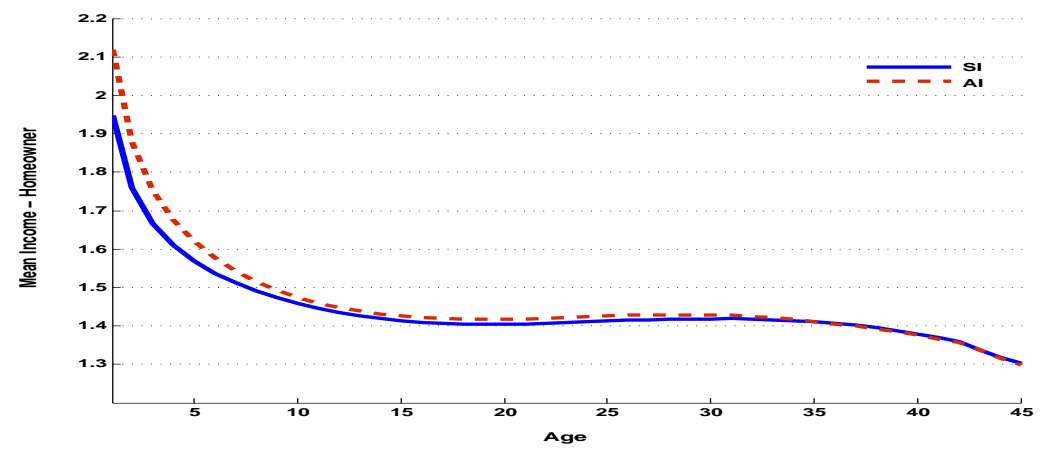

Figure 6: Mean Income of Renter over the Life Cycle in SI vs AI

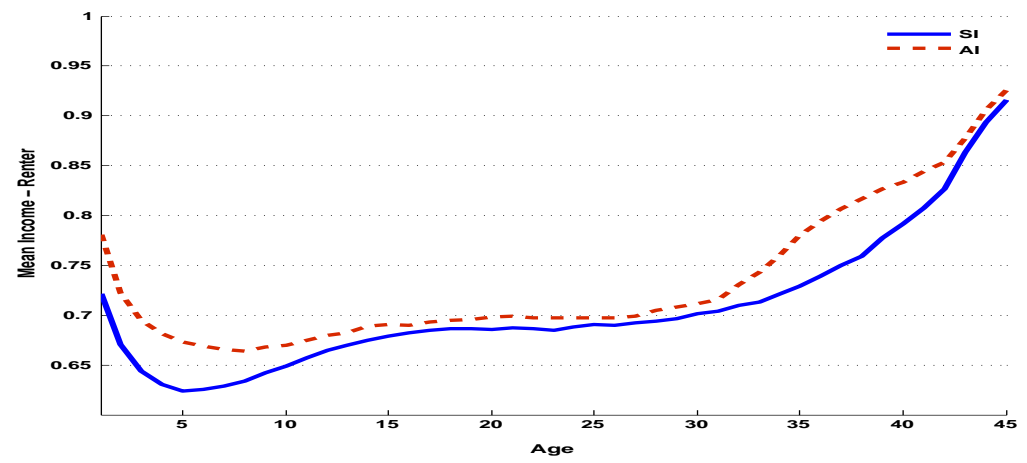


Figure 7: Debt-to-Income Ratio over the Life Cycle in SI vs AI

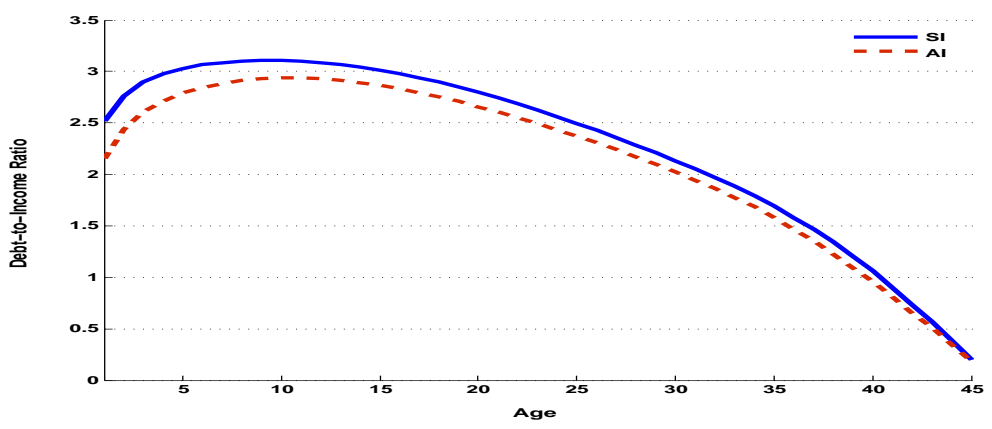

Figure 8: Debt-Service Ratio over the Life Cycle in SI vs AI

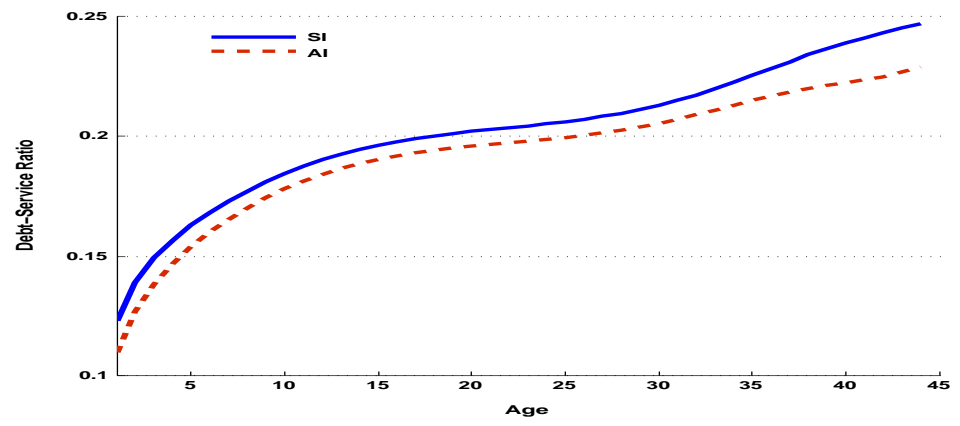


Figure 9: Consumption of Homeowner over the Life Cycle in SI vs AI

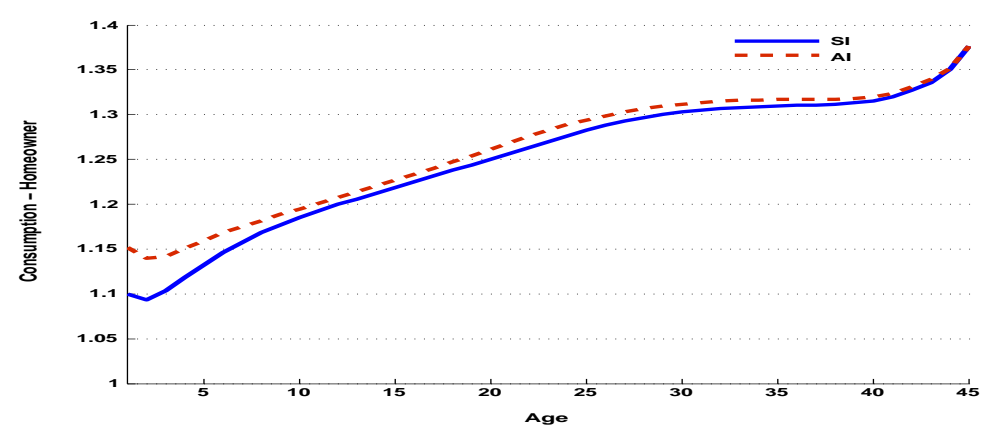

Figure 10: Consumption of Renter over the Life Cycle in SI vs AI

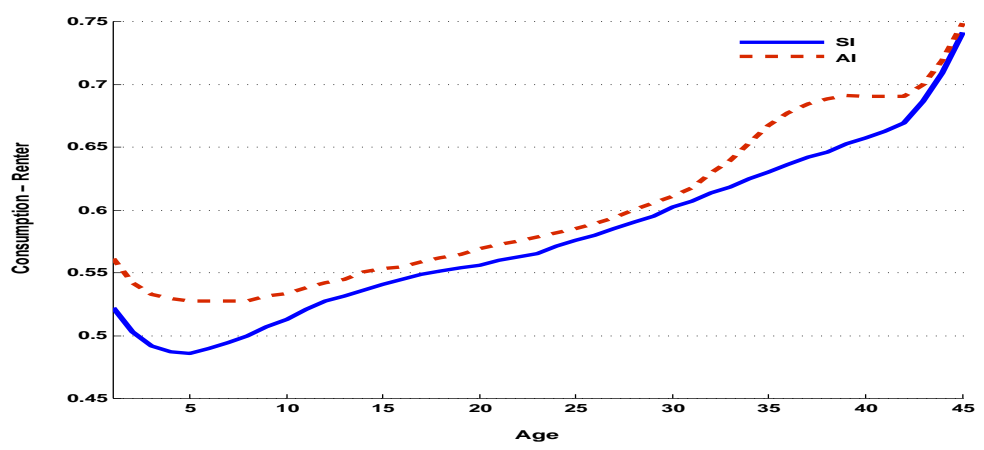


Figure 11: Illustration of Equilibrium

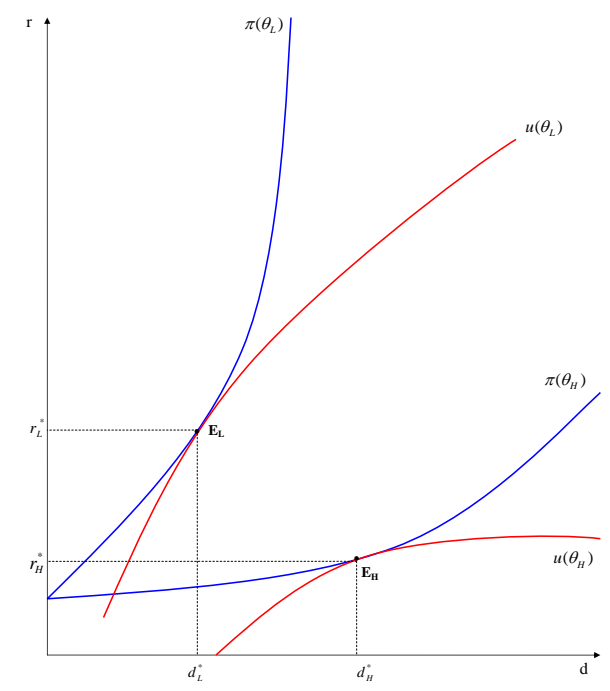

(a) Symmetric Equilibrium

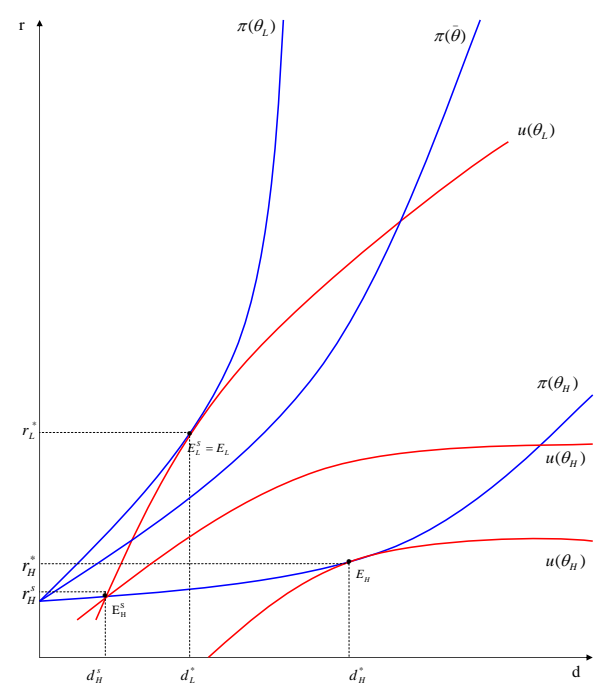

(c) Separating Equilibrium

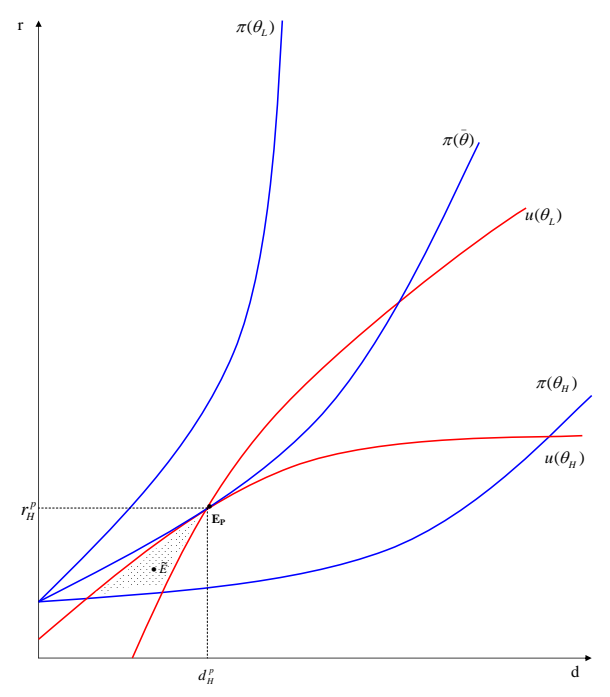

(b) No Pooling Equilibrium

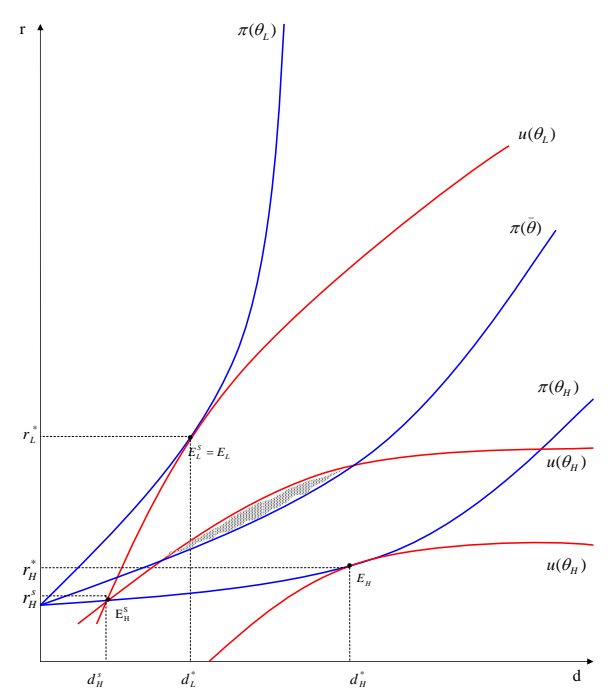

(d) No Separating Equilibrium 